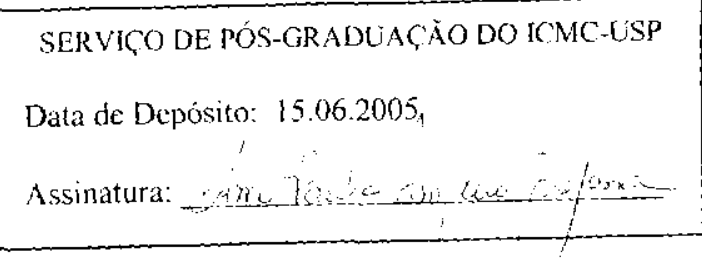

\title{
Modelador e simulador do sistema visual humano
}

Rodrigo Silva Duran

Orientador: Prof. Dr. Lais Gllstavo Tonato

Dissertaçào apresentada ao Instituto de (iencias Matemáticas de Computaçào - ICMC-LSP, como parte dos requisitos para Matemática Computacional. em Ciencias de Computaça e

USP - Săo Carlos

Junho/2005 
Aluno: Rodrigo Silva Duran

A Comissão Julgadora:

Prof. Dr. Luis Gustavo Nonato

Profa. Dra. Liliane Ventura Schiabel

Prof. Dr. Odemir Martinez Bruno

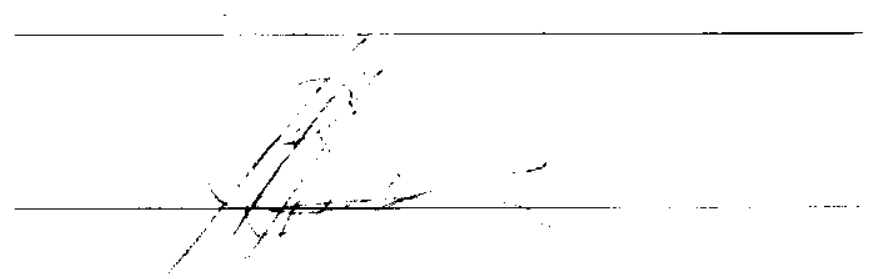




\section{Conteúdo}

$\begin{array}{lc}\text { Lista de Figuras } & \text { iii }\end{array}$

1 Introdução 2

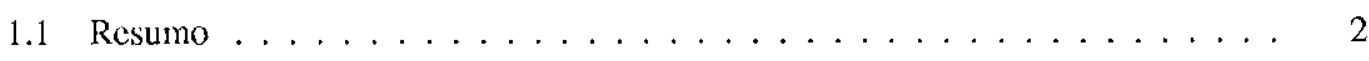

1.2 Abstract ....................... 3

1.3 Organização do trabalho $\ldots \ldots \ldots \ldots \ldots \ldots \ldots \ldots$

2 Trabalhos Relacionados $\quad 5$

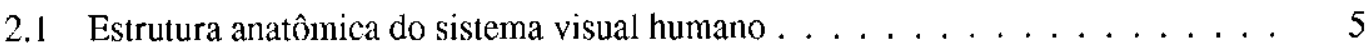

2.2 Modelos de Olhos . . . . . . . . . . . . . . . . . . . . 7

2.3 Simulações e Validações . . . . . . . . . . . . . . . . . . 11

3 Modelagem computacional do olho humano 17

3.1 Modelagem da Retina . . . . . . . . . . . . . . . 17

3.2 Modelagem da Cónea . . . . . . . . . . . . . . . . 21

3.3 Modelagem das lentes do cristalino . . . . . . . . . . . . . . . . . . 24

4 Lançamento de Raius

4.1 Estrutura SHE . . . . . . . . . . . . . . . . . . . 26

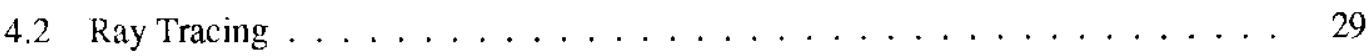


5.1 Lançamento dos Anéis de Plácido $\ldots \ldots \ldots \ldots$

5.2 Simulaçào de Inversão de Inagem . . . . . . . . . . . . . . . . . 35

5.3 Point Spread Function $\ldots \ldots \ldots \ldots \ldots \ldots$

5.4 Simulação de Wavefront $\ldots \ldots \ldots \ldots \ldots \ldots$. . . . . . . . . . 42

5.5 Simulação de Projeção de Imagens . . . . . . . . . . . . . . . . . 43

6 Conclusão e 'Trabalhos Futuros 46

$\begin{array}{ll}\text { Bibliografia } & 47\end{array}$ 


\section{Lista de Figuras}

2.1 Estrutura anatômica do olho humano (Helga Kolb, 2004) . . . . . . . . . . . . 6

2.2 Modelo esquemático do olho por H.V. Helmholtz (von Helmholtz, 1909) . . . . . 8

2.3 Modelo reduzido de Emsley (L.N. Thibos, 1999a) f . . . . . . . . . . . 9

2.4 Modelo esquemático de Koiijman. As linhas pontilhadas representam as superfícics parabólicas cm comparação às superfícies esféricas mostradas nas linhas sólidas. (Kooijman, 1983) . . . . . . . . . . . . . . . . . . . . 10

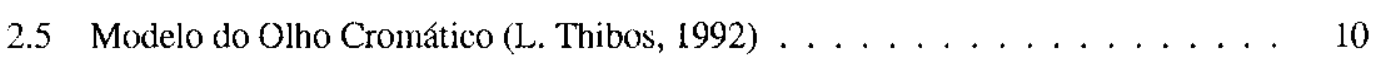

2.6 Modelo de Gullstrand, Modelo Reduzido e Olho de Indiana (L.N. Thibos, 1999a) 12

2.7 Point Spread Function de dois pacientes (J.J. Camp, 1990). . . . . . . . . . . . 13

2.8 Poder de refração Axial (B. Barsky, 1998). . . . . . . . . . . . . . . . . . 14

2.9 Poder de refração Instantâneo (B. Barsky, 1998). . . . . . . . . . . . . . . 15

2.10 Distância Retinal (B. Barsky, 1998)， . . . . . . . . . . . . . . . . 15

2.11 Distância de foco (B. Barsky, 1998) . . . . . . . . . . . . . . . 16

3.1 Etapa inicial da modelagem da retina . . . . . . . . . . . . 18

3.2 Etapa inicial da modelagem da retina com 2 camadas de refinamento . . . . . . . 19

3.3 Processo de refinamento dos triângulos . . . . . . . . . . . . . . . . 19

3.4 Modelo com três camadas e três refinamentos na última camada . . . . . . . . 20

3.5 Modelo com três camadas e três refinamentos com os buracos corrigidos . . . . . 21

3.6 Processo de triangulação da cónea . . . . . . . . . . . . . . . . . . . . 22

3.7 Córnea com ceratocone triangulada . . . . . . . . . . . . . . . 23 
3.8 Córnea com ceratocone triangulada em menor resolução $\ldots \ldots \ldots$

3.9 Modelo computacional das lestes do cristalino. . . . . . . . . . . . . . . 24

3.10 Modelo computacional final do sistema visual humano. . . . . . . . . . . . 25

4.1 Malha triangular $\mathrm{c}$ entidades da estrutura ................ 28

4.2 Diagrama de Classes da estrutura SHE . . . . . . . . . . . . . . . . . 29

4.3 Coordenadas do ponto $\mathrm{P} \ldots \ldots \ldots \ldots \ldots$

4.4 Esquema do processo de refração do raio incidente na cónea . . . . . . . . . 33

5.1 Projeção dos Anćis de Plácido na Córnca . . . . . . . . . . . . . . 35

5.2 Esquema do processo de lançamento e refração de raios no interior da superfície

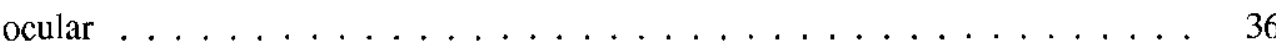

5.3 Imagem retinal formada através da projeção dos anéis de Plácido em uma cónca

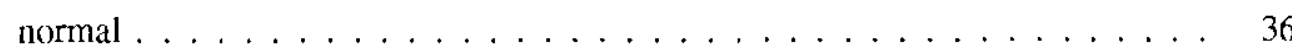

5.4 Imagem retinal formada através da projeção dos ancis de Plácido cm uma cónca

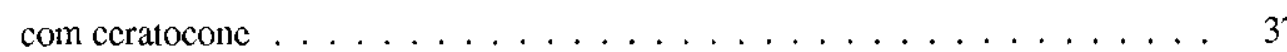

5.5 Imagem retinal formada através da projeção dos anéis de Plácido em uma córnea com astigmatismo fortc . . . . . . . . . . . . . . 37

5.6 Imagem retinal fonmada através da projeção dos anćis de Plácido em uma cónea com astigmatismo suave $\ldots \ldots \ldots \ldots \ldots \ldots$

5.7 Lançamento de raios a partir de um objeto com orientação definida em vista lateral 38

5.8 Imagem retinal formada através da projeção da scta em uma córnea normal . . . 39

5.9 Imagem retinal formada através da projeção da seta $\mathrm{em}$ uma córnca com ccratocone 39

5.10 Imagem retinal formada através da projeção da seta $\mathrm{cm}$ uma cónca com astigmatismo forte . . . . . . . . . . . . . . . . . . . . . . . .

5.11 Mapa de Point Spread Function produzido através de uma cónjea hemétrope perfeita. 40

5.12 Mapa de Point Spread Function produzido através de uma cónca com ceratocone. 41

5.13 Mapa de Point Spread Function produzido através de uma cónca com astigmatismo forte. ........................ 
5.14 Ilustração do processo de obtenção da frente de onda. . . . . . . . . . . . . . 43

5.15 Imagem projetada na retina através de uma cónea nromal. . . . . . . . . . . . 44

5.16 Imagem original utilizada para projeção. . . . . . . . . . . . . . . 45

5.17 Imagem projetada na retina através de uma cónea com ceratocone. . . . . . . . . 45 


\title{
Agradecimentos
}

\author{
Aos meus pais que sempre me apoiaram em todos os meus projetos na vida, \\ à minha namorada, que muito me apoiou nos momentos difíceis, \\ ao meu orientador Luis Gustavo Nonato, por seu imenso conhecimento e paciência ainda maior, \\ aos professores Odemir Martinez c Luis Alberto de Carvalho, pela inestimável contribuição ao \\ projeto, \\ ao Fabio Margarido, companheiro de todas as horas no projeto, \\ ao apoio financeiro concedido pela FAPESP.
}




\section{Capítulo 1}

\section{Introdução}

\subsection{Resumo}

A modelagem computacional do olho humano tem sido largamente estudada por diferentes setores da comunidade científica e tcenológica. Uma das principais razões para esse crescente interesse é a possibilidade de reproduzir propriedades opticas por meio de simulações computacionais, tornando possível o desenvolvimento de dispositivos eficientes para tratar e corrigir os problemas da visão. Os resultados dessá intensa pesquisa já podem ser observados nos equipamentos para medições de distorções do sistema visual, como os topógrafos de cónea, que sofreram uma rápida cvolução nos últimos anos.

Diferente do que ocorreu em outras áreas da ciência, como na medicina por cxemplo, o aprimoramento dos dispositivos de medição ocular não tem influenciado de forma significativa a modelagem computacional do sistema visual. Como pode ser notado a partir da literatura (Gullstrand, 1909), (Emsley, 1952), (Kooijman, 1983), 4(L.N. Thibos, 1999a), a maioria dos trabalhos descritos ainda emprega modelos puramente teóricos na simulação dos processos visuais, não fazendo uso das informaçôes adquiridas pelos equipamentos modernos desenvolvidos para a of talmologia.

Esse projeto de mestrado explora exatamente esse aspecto ainda pouco investigado da modelagem do sistema visual. Em conjunto com membros do grupo de optica oftalmológica do Departamento de Física da USP de São Carlos, o projeto propõe um arcabouço computacional 
que viabiliza a utilização de dados reais na modelagem e simulação do sistema visual humano. Essa nova abordagem possibilita a investigação individualizada do sistcma óptico, possibilitando a construção de novas técnicas as quais possibilitarão inferir dados de vital importância cm exames médicos, exames cstes anteriormente apenas disponíveis a um alto custo, isto quando existentes.

\subsection{Abstract}

The computational modeling of the human eye has been wide studied for different sectors of the scientific and technological community. One of the main reasons for this increasing interest is the possibility to reproduce optic properties by means of computational simulations, becoming possible the development of efficient devices to treat and to correct the problems of the vision. The results of this intense rescarch already can be observed in the equipment for measurements of distortions of the visual system, as the corneal topographers, who had suffered a fast evolution in the last years.

Different of that it occurred in other areas of science, as in the medicine, for example, the improvement of devices of ocular measurement has not influenced in a significant form the computational modeling of the visual system. As it can be noticed from literature, (Gullstrand, 1909), (Emsley, 1952), (Kooijman, 1983), (L.N. Thibos, 1999a), the majority of the described works still uses models purely theoreticians in the simulation of the visual processes, not making use of the information acquired for the developed modern equipment for the ophthalmology.

This project explores this aspect still little investigated of the modeling of the visual system. In set with members of the group of ophthalmologic optics of the Department of Physics of the USP/ São Carlos, the project propose a computational sketch that make possible the use of real data in the modeling and simulation of the human visual system. This new boarding make possible the individual inquiry of the optic system, making possible the construction of new techniques used to infer vital data in medical investigations. 


\subsection{Organização do trabalho}

A fim de contextualizar o trabalho realizado, no capítulo 2 é apresentado um levantamento bibliografico dos principais trabalhos voltados para a modelagem e simulação do sistema visual humano. O capítulo 3 apresenta o processo realizado na modelagem computacional das estruturas oculares da retina, cónca e cristalino. O capítulo 4 apresenta a metodologia utilizada para construir os algoritmos que simulam as propriedades opticas do sistema visual humano, tal com os lançamentos de raios e o processo de refração da luz dentro do olho humano. O capítulo 5 contém os resultados c simulações implementadas pelo projeto c o capítulo 6 apresenta a conclusão ao trabalho bem como trabalhos futuros relacionados. 


\section{Capítulo 2}

\section{Trabalhos Relacionados}

Este capítulo apresenta uma breve descrição da estrutura biológica do olho humano, pois o projeto utiliza dados in vivo na construção do modelo computacional do sistema visual humano, tornando a completa comprecnsão de todo o funcionamento e organização anatômica do olho humano crucial. Postcriormente serão apresentados os modelos esquemáticos mais difundidos na litcratura, modelos esses que servem de base para a construção do modelo proposto pelo projeto de mestrado. Alguns trabalhos relacionados com a simulação de aspectos do sistema visual humano scrão apresentados na parte final do capítulo.

\subsection{Estrutura anatômica do sistema visual humano}

O olho humano é uma complexa estrutura biologica que pode ser descrita anatomicamente como um globo de forma quase csférica com $23 \mathrm{~mm}$ de diâmetro. Visualmente o olho humano pode ser considerado como um sistema óptico positivo que refrata a luz incidente em sua porção posterior, chamada retina, para formar uma imagem real (Pedrotti, 1998).

As principais estruturas oculares são apresentadas na figura 2.1. A cónea $\mathfrak{c}$ um tecido transparente abundante em células nervosas com aproximadamente $12 \mathrm{~mm}$ de comprimento transversalmente e $0.6 \mathrm{~mm}$ de espessuta em seu centro. Com um índice de refração de 1.376, a córnea 6 responsável por cerca de $73 \%$ do poder de refração do olho. A iris é um diafragma responsável 


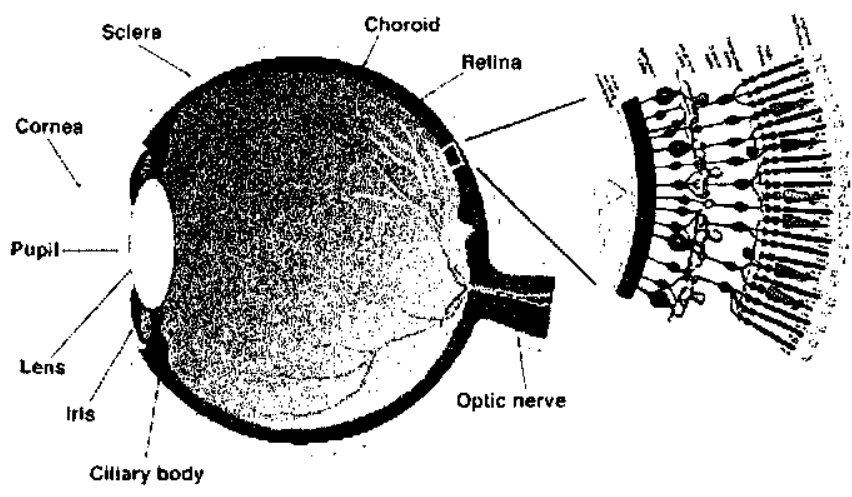

Figura 2.1: Estrutura analômica do olho humano (Helga Kolb, 2004).

pelo controle da quantidade de luz que adentra o olho. Tal funçăo é desempenhada através de dois músculos que regulam a abertura $\mathrm{cm}$ seu centro, denominada pupila. As lentes do cristalino fornccem o ajuste fino neccssário para a formação das imagens. Com uma esırutura laminar muito intrincada, as lentes do cristalino podem alterar o seu formato visando a formação de uma imagem mais nílida. Em seu estado relaxado as lentes assumem uma forma plana, fornecendo seu menor grau de refração. Ao assumir um estado mais curvado, as lentes do cristalino oferecem maior poder de refração, poder este necessário quando o olho está focado em objelos muito próximos, por excmplo. Devido a tais características, as lentes do cristalino possucm índice de refração nãohomogênco, variando de $1.41 \mathrm{~cm}$ scu centro a 1.39 na periferia das lentes. Na porção posterior do olho está localizada a retina, uma rede composta por milhões de fotoreceptores chamados cones c bastonetes. Os bastonctes são extremamente sensívcis a pouca luz mas incapazes de distinguir cores, cstando $\mathrm{cm}$ número de 100 milhões aproximadamente e localizados mais densamente na direção da periferia da retina. Já os cones são estruturas sensíveis a cor, estando cm número bem menor que os bastonctes, na casa de 10 milhõcs. Os concs cstão concentrados cm uma região especializada no centro da retina chamada mácula. A mácula é uma região de especial interesse pois nela cstá licalizada a fovea centralis, a área de maior acuidade visual do olho humano. 


\subsection{Modelos de Olhos}

Existem diferentes abordagens para a modelagem computacional do sistema visual humano, scndo os modelos esquemáticos c os modelos reduzidos os mais utilizados. Os modelos esquemáticos buscam criar modelos precisos para o sistema ocular, procurando respcitar a anatomia do olho humano. Embora possam representar de forma bastante satisfatoria as propricdades e funcionalidades do sistema visual, para fins de simulação computacional, os modelos esquemáticos podem ser demasiadamente complexos, necessitando de simplificações. Os modelos reduzidos procuram reproduzir as características opticas do sistcma ocular humano, embora tais modclos dificilmente sigam fielmente todas as estruturas anatômicas presentes no olho humano. As simplificaçōes introduzidas pelos modelos reduzidos, os quais algumas vezes chegam a constituir-se de apenas uma única estrutura refratária, ajudam consideravelmente nos cálculos de problemas simples. Para problemas cuja meta seja atingir a performance real do sistema visual humano tais modelos podem tornar-se incomplctos.

Um dos primeiros trabalhos relacionados com a modelagem do olho humano é devido a H.V. Helmhotz (von Helmholtz, 1909). Esse modelo esquemático dito quase cxato tenta representar um olho com funcionamento biológico correto, incluindo a maioria das estruturas anatômicas, cmbora os valores dos índices de refraçăo bem como alguns valores de rajo de curvatura propostos não sejam biologicamente consistentes. Apesar de tais điscrepâncias com o modelo biológico, o modelo esquemático proposto por Helmotz, mostrado na figura 2.2, possui propricdades opticas consideradas fiéis ao olho humano.

Gullstrand (Gullstrand, 1909) propõe simplificaçōes no modelo esquemático de Hclmhotz, ao considerar a córnea como sendo constituída de uma única superfícic, o mesmo valendo para as lentes do cristalino $\mathrm{c}$ a retina, o que reduz consideravelmente a complexidade do modelo. $\mathrm{O}$ modelo reduzido de Emsley (Emslcy, 1952), derivado a partir do modelo esquemático de Gullstrand, é um dos mais difundidos, principalmente por sua simplicidade. Nesse modelo apresentado na figura 2.3, apenas a retina e a cómea são representadas, considerando o olho como uma superfície única, com poder de refração de 60 dioptrias e com um meio interno possuindo índice de refração 


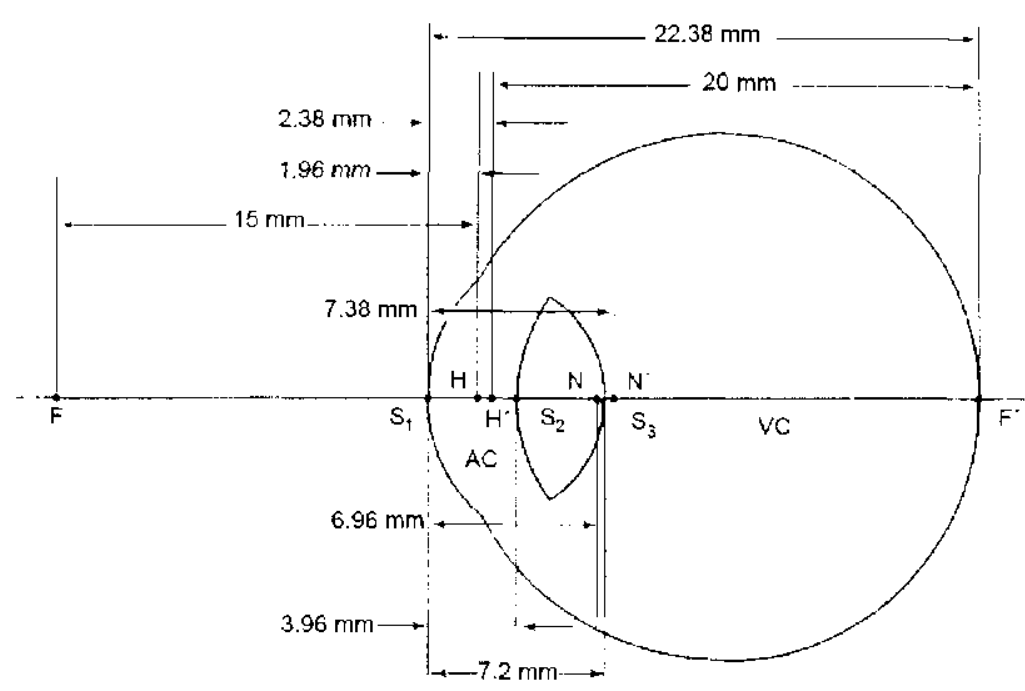

Figura 2.2: Modelo esquemático do olho por H.V. Helmholtz (von Helmholtz, 1909)

\section{de 1.333}

Os modelos descritos anteriormente empregam superfícies esféricas na modelagem dos componentes do olho, o que inviabiliza a realização de simulações realísticas. Dados obtidos em pesquisas com olhos humanos reais mostram que tais modelos possuem valores muito elevados de aberração esférica, não condizentes com os dados biológicos obtidos. Visando uma maior conformidade com experimentos reais, Lotmar (Lotmar, 1971) propõe um modelo, também baseado cm Gulstrand, onde superfícies parabólicas substituem os modelos esféricos. Embora os valores para as superficies propostas não possuam fundamentação anatômica, os resultados obtidos são condizentes com experimentos realizados. Ainda nessa linha, Kooijman (Kooijman, 1983) sugere modelar a cónea e as partes posterior $\mathrm{c}$ anterior do cristalino com clipses, parábolas $\mathrm{c}$ hipérboles respectivamente, como mostrado na figura 2.4. Tal modelo foi empregado visando cstudar os cfcitos da iluminação na retina e como o tamanho da pupila e modificaçōes na forma das superfícies oculares afctam tal iluminaçăo. Os cálculos foram realizados utilizando tanto superfícies parabólicas quantos esféricas para efeito de comparação. Como resultado do estudo, Kooijman diz. 


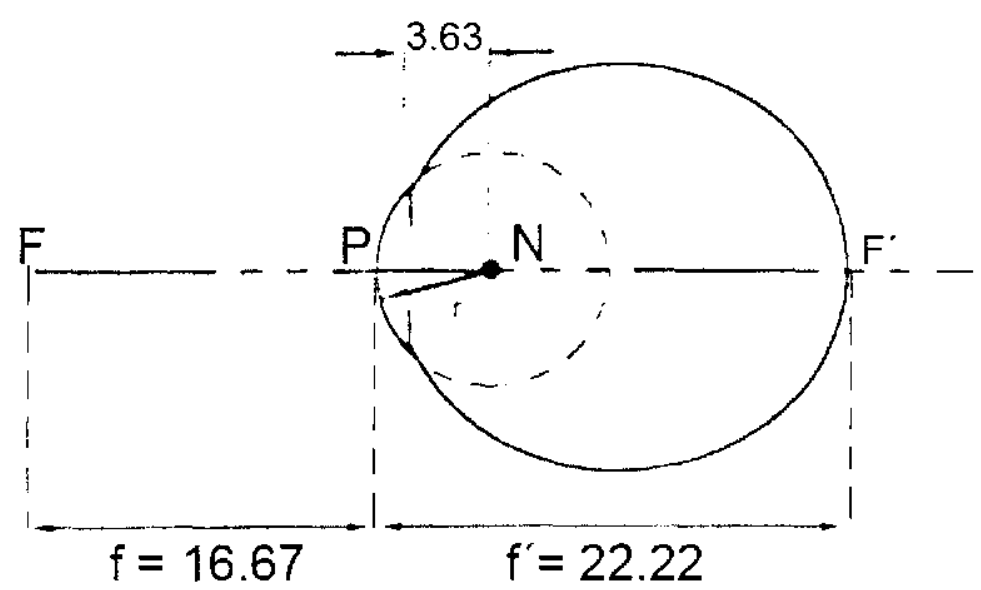

Figura 2.3: Modelo reduzido de Emsley (L.N. Thibos, 1999a)

que a distribuição da luz na retina é quase homogênea $c$ tal homogeneidade não é relevantemente influenciada tanto pela forma das superfícics quanto pelo tamanho da pupila.

Navarro (R. Navarro, 1985) propōe uma abordagem semelhante à de Kooijman, sugerindo que quádricas parametrizadas scjam empregadas na modelagem das lentes do sisterna 6ptico visando o cálculo de aberraçōes no cixo. O modelo considera um sistema b́ptico formado por quatro superfícics quádricas, cada qual definida por scu raio c asfericidade, centradas e com simetria rotacional. Ao empregar superfícies parabólicas, Navarro visa condicionar scu modelo esquemático a mediçōes realizadas de aberração esférica, empregando ainda uma técnica para simular a aberração cromática do olho humano. O modelo esquemático ainda propõc a modelagem do efeito de acomodação das Ientes do cristalino através de um esquema paraxial que utiliza uma função logarítmica para ajustar as superfícies das lentes a cada estado de acomodação.

Thibos (L. Thibos, 1992) propõe um novo modelo reduzido denominado "Olho Cromático", apresentado na figura 2.5 o qual visa aprimorar a simulação da abcrração cromática. O modelo tenta suprir algumas deficiências detectadas $\mathrm{cm}$ modelos anteriores, utilizando técnicas mais avançadas para medir a aberração cromática e a partir de tais dados infcrir novas equações para o cál- 


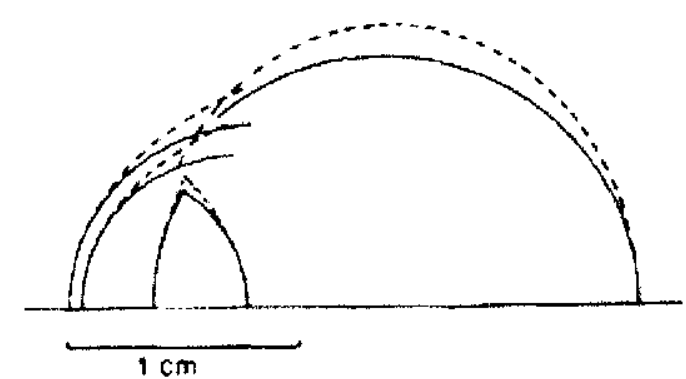

Figura 2.4: Modelo esquemático de Koiijinan. As linhas pontilhadas representam as superfícies parabólicas em comparação às superfícies esféricas mostradas nas linhas sólidas. (Kooijman, 1983)

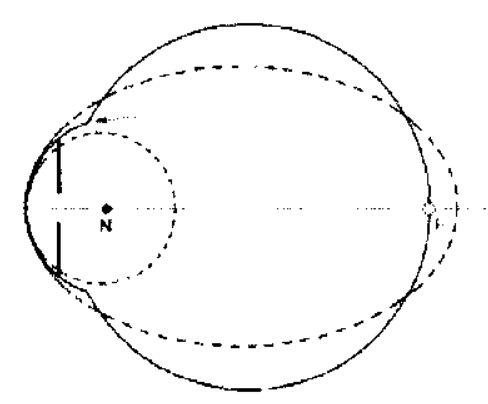

Figura 2.5: Modelo do Olho Cromático (L. Thibos, 1992)

culo do índice de refração. O oho cromático emprega superfícies clípticas c introduz uma pupila ao modelo, o que fornece a capacidade de simular tanto efeitos da difração quanto as aberrações transversais de diferença cromática c magnificação. Vale salientar que tal modelo deliberadamente possui aberração esférica nula.

Posteriormente, Thibos (L. Thibos, 1997) introduz um maior grau de liberdade ao modelo visando simular os efeitos da aberração esférica, ausentes no olho cromático. A superfícic clíptica do modelo anterior é substituída por uma família de modelos de simetria rotacional, construídos a partir de superfícies quádricas de revolução. Tal família é definida pela cquação 2.1 , onde $p$ éo parâmetro da forma da superfície $\mathrm{e} r$ é o raio paraxial. De modo a simplificar o modelo, os cixos optico, visual, acromático e de fixxação são assumidos como coincidentes, a pupila está centrada no eixo visual e a fovea está localizada no eixo óptico, como pode ser observado na figura 2.6. Este 
novo modelo foi chamado de "Olho de Indiana". Em outro trabalho, Thibos (L.N. Thibos, 1999b) altera o olho de Indiana movendo a pupila $0,6 \mathrm{~mm}$ e assim mostrando que tal modelo modificado também esta apto a demonstrar os efeitos do astigmatismo oblíquo.

$$
z=\frac{x^{2}+y^{2}+p z^{2}}{2 r}
$$

\subsection{Simulações e Validações}

De modo a aferir se modelos esquemáticos podem realmente simular o comportamento óptico do olho humano, Doshi (J. Doshi, 2001) apresenta um conjunto de experimentos, realizados em indivíduos vivos com aberraçōes na visão, e compara os resultados de tais experimentos com simulações realizadas a partir dos modelos de Kooijman, Olho Cromático e Olho de Indiana. De acordo com Doshi, todos os modelos apresentaram resultados satisfatórios, cmbora o melhor descmpenho em scus experimentos tenha sido alcançado com o Olho Cromático.

Com o desenvolvimento dos equipamentos de medição ópticos, tal como o topógrafo de cornea, foi possível obter dados mais confiávcis e precisos das estruturas oculares. Aproveitando-se de tais avanços, Camp (J.J. Camp, 1990) desenvolveu um método para avaliar o efeito de irregularidades na superfície da cónea na performance optica do olho. Um sistema de análise optica fornece as coordenadas polares de 2560 pontos na superfícies da cónea. Na etapa seguinte, é realizado o raytracing cm tais pontos e construída uma Point Spread Function projetando os raios cm um plano de referência, geralmente o plano de melhor foco. Na figura 2.7 é possível notar que o paciente com cónea sem aberrações (primeira figura a esquerda) produz um sinal quase totalmente centrado no sinal de pico, enquanto um paciente com ceratocone produz um sinal disperso, reforçando a idéia de que nem todos os raios de luz incidentes atingem a região de melhor foco. De modo a inferir como tais pacientes enxergam, Camp produziu imagens das letras de Snellen, convoluindo tais imagens com as Point Spread Functions calculadas anteriormente. Utilizando como base o modelo de olho de Emsley, Carvalho (L. Carvalho, 2002) realiza um trabalho muito semelhante, utilizando dados in vivo para modelar a cónea. 


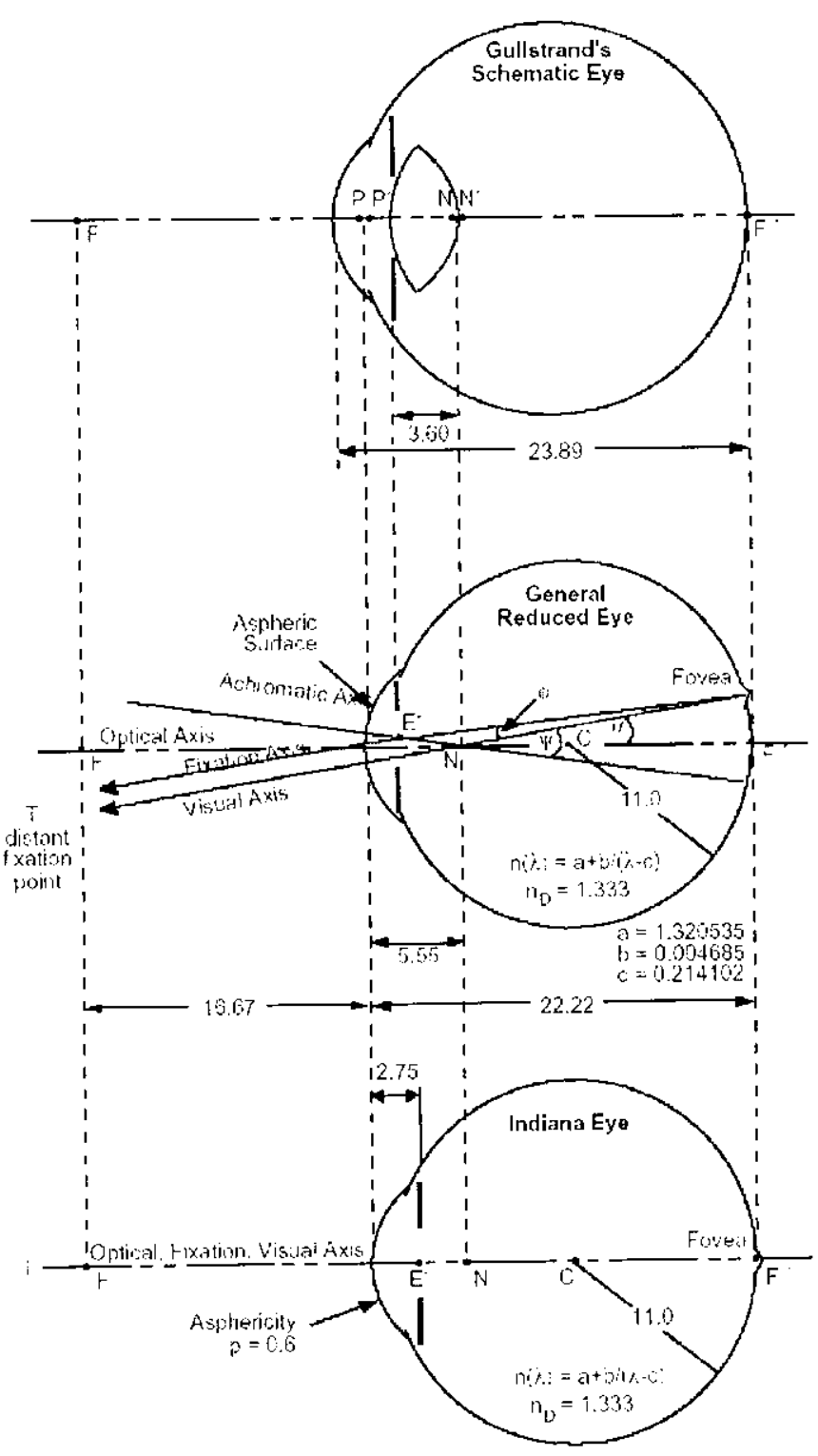

Figura 2.6: Modclo de Gullstrand, Modelo Reduzido e Olho de Indiana (L.N. Thibos, 1999a) 

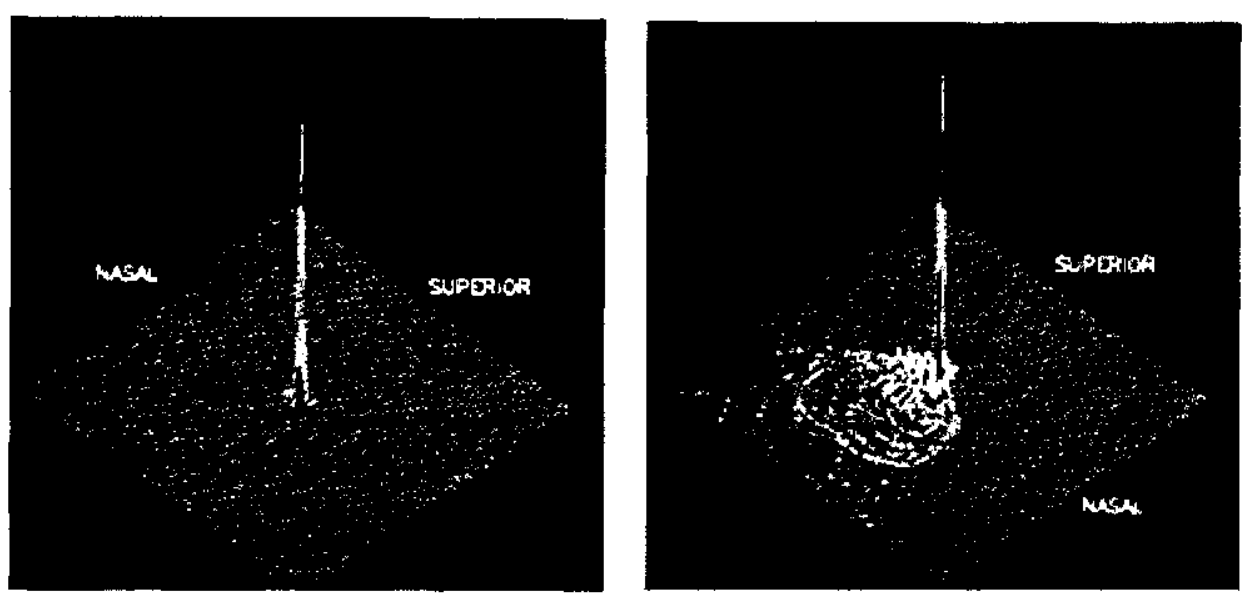

Figura 2.7: Point Spread Function de dois pacientes (J.J. Camp, 1990).

Uma modelagem tcórica bastante interessante do cristalino e feita por Smith (Smith, 2003), que discute as caractcrísticas opticas das lentes do cristalino $e$ apresenta uma modelagem matemática para o seu funcionamento. Tal modelagem pode ser bastante útil $\mathrm{cm}$ futuras implementaçõcs de modelos mais realísticos do funcionamento das lentes do cristalino.

Atualmente existem alguns simuladores que tentam medir a acuidade visual dos pacientes através de métricas opticas. Barsky (B. Barsky, 1998) implementa um software denominado $C$ WhatUC o qual revela o quão bem a cornea foca raios de luz paralelos na fovea, fornecendo instrumentos de visualização científica para interpretação dos dados. A córnea é reconstruída através de uma spline que utiliza dados reais medidos por um topógrafo de córnea. Para simular a contribuição da cónnea na acuidade visual são propostas quatro métricas, usando um modclo de olho muito simples sem lentes do cristalino c considerando a cónea como um material com índice de refração constante de 1.3375. As métricas propostas são as seguintes:

- Poder de Refração Axial: A métrica de poder de refração axial (ARP) em um ponto da cónea é definida como o quociente entre o índice de refração da cónnea c a distância entre o ponto na cónea $\mathrm{e}$ o ponto de interseção no cixo (figura 2.8). Tal medida fornece mapas que geralmente facilitam a identificação de astigmatismo. 


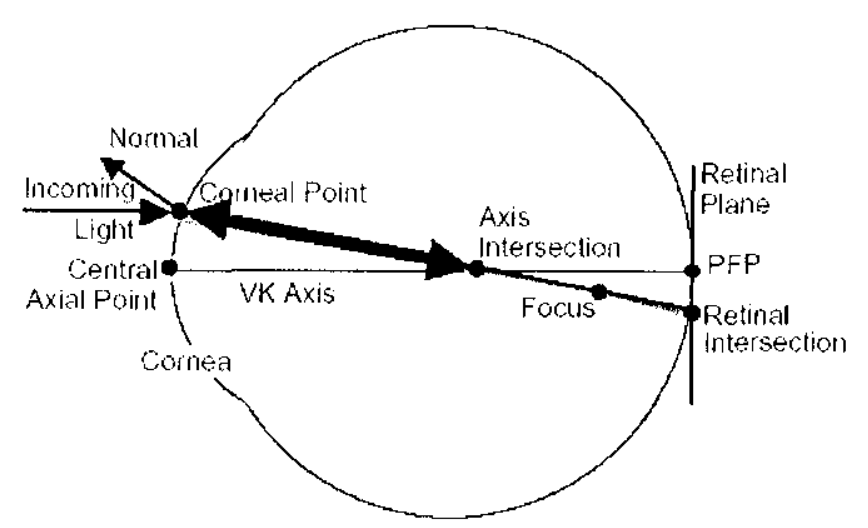

Figura 2.8: Poder de refração Axial (B. Barsky, 1998).

$A R P=-\frac{n}{\text { Distancia } 3 D(\text { Ponto }- \text { do }- \text { Cornea, Interseccoo - no - eixo) }}$

- Poder de Refração Instantâneo:

A métrica de poder de refração instantâneo IRP cm um ponto da córnea é definida como o quociente entre o índice de refração da córnea e a distância entre o ponto na cómea c o ponto focal (figura 2,9). Essa métrica ilustra a quantidade de aberração esférica presente no modelo óptico utilizado.

$$
I R P^{\prime}=\frac{n}{\text { Distancia3D('onto }- \text { da }- \text { Cornea, P'onto }- \text { Focal })}
$$

- Distância Retinal:

A métrica de distância retinal (RD) é definida para cada ponto da córnca como sendo a distância do ponto focal paraxial (PFP) ao ponto de intersecção na retina (figura 2.10). Como o plano da retina por definição contém o PFP, ambos estão em um mesmo plano logo a distância torna-se um cálculo de distância bi-dimensional planar. Em um olho perfeito, 


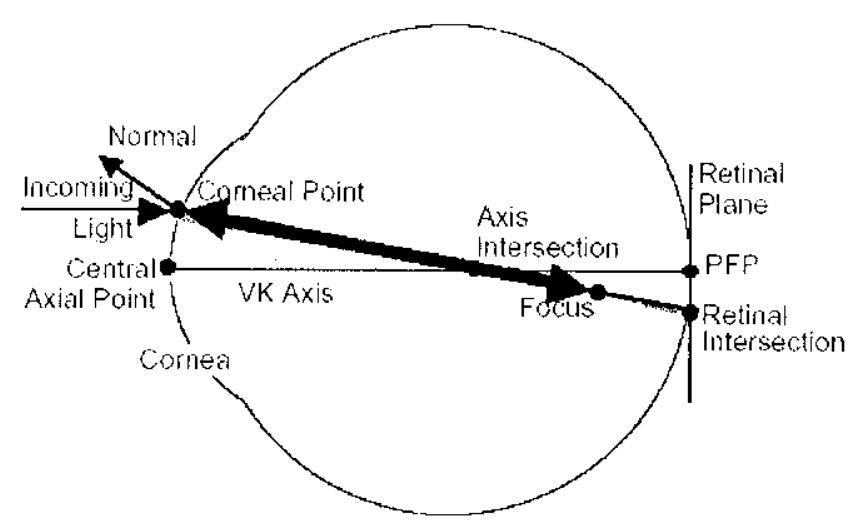

Figura 2.9: Poder de refração Instantâneo (B. Barsky, 1998).

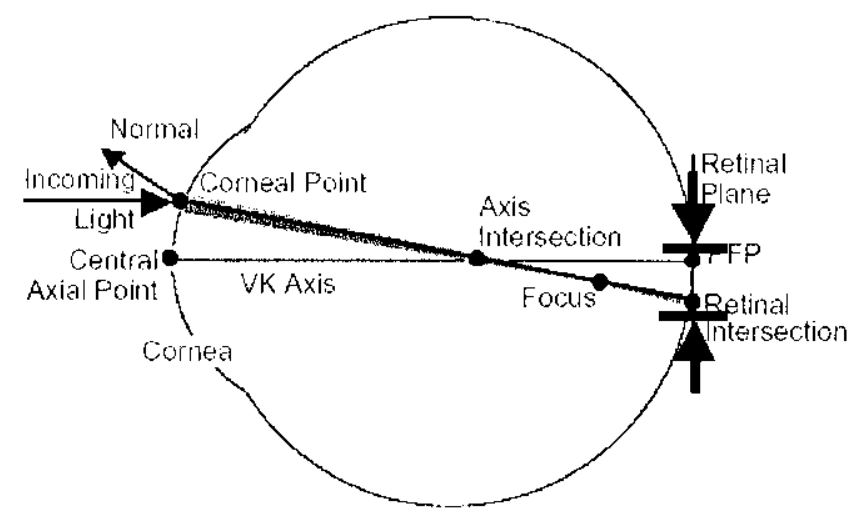

Figura 2.10: Distância Retinal (B. Barsky, 1998).

raios de luz paralclos convergem em um ponto de foco localizado no PFP, e neste caso a distância retinal scria zcro. Esta métrica fonnece uma noção da aberração esférica lateral.

$R D=$ Distancia $2 D($ Interseccao - na - Retina,$P F I)$

- Distância de foco:

A distância de foco (FD) para cada ponto na cónca é a distância do ponto focal ao ponto focal paraxial (figura 2.11). Em um olho perfeito os raios de luz que incidem paralclamente 


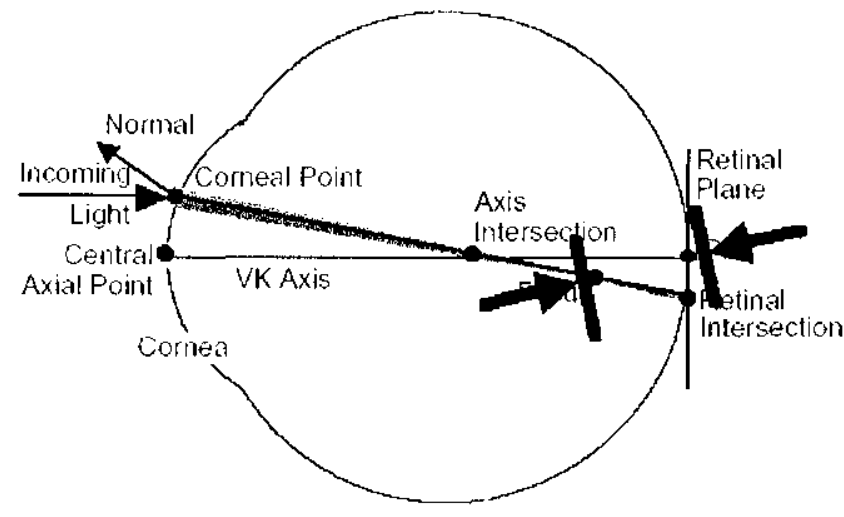

Figura 2.11: Distância de foco (B. Barsky, 1998).

convergem em um ponto focal localizado no PFP c consequentemente a distância de foco seria zero nesse caso.

Como pode ser visto, poucos trabalhos empregam dados reais na modelagem e simulação do sistema visual humano. É cvidente que a utilização de dados reais possibilita, além da realização de simulações realísticas, o estudo de fenômenos que dificilmente poderiam ser analisados sem tal recurso. 


\section{Capítulo 3}

\section{Modelagem computacional do olho}

\section{humano}

A abordagem adotada no projeto de mestrado foi utilizar malhas triangulares tridimensionais para simular as estruturas anatômicas mais importantes do sistema visual humano. Este capítulo apresenta a metodologia implementada para a construção dos modclos computacionais da retina, cómea e lentes do cristalino.

\subsection{Modelagem da Retina}

A modelagem da retina foi realizada através de uma abordagem de refinamento sucessivo. Tal abordagem foi usada visando simular a distribuição dos cones e bastonetes no olho humano. É sabido que nas regiões anteriores da retina, mais próximas à cónea, a concentração de fotoreptores é muito menor se comparada à região posterior, sobretudo na região da fovea. O modelo reduzido de Emsley (Emsley, 1952) foi cscolhido como base da modelagem por sua simplicidade. Todas as medidas especificadas no modelo foram respcitadas pela modelagem de modo a tornar a malha tri-dimensional o mais fiel possível.

A primeira parte da modelagem consiste em construir um modelo básico da retina, bascado nas medidas do modelo de Emsley, tendo como entrada o número de camadas de refinamento c o 


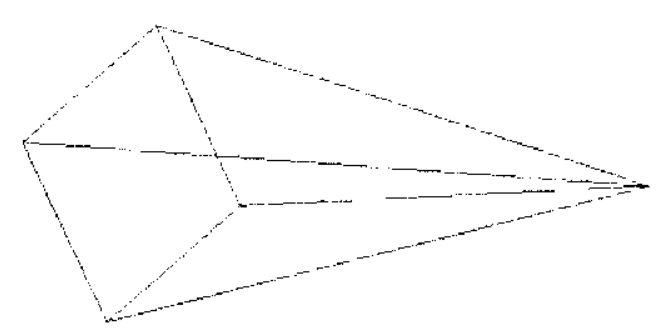

Figura 3.1: Etapa inicial da modelagem da retina

nível de refinamesto na camada mais refinada, nesse caso a camada posterior da retina onde está situada a fovea. Os cinco pontos iniciais do modelo são : quatro na sccção circular existente no modelo, onde é encaixado o modelo da córnca, c o outro no fundo da retina, como mostrado na figura 3.1. Além desses, os outros pontos do modelo inicial dependem do número de camadas que serāo construídas: caso o modelo tenha duas camadas, haverá mais um plano intermediário com quatro pontos no modelo como mostrado na figura ??; caso tenha três camadas, mais dois planos com quatro pontos cada, e assim por diante.

Construído o modelo inicial, tem início a ctapa de refinamento sucessivo das camadas, iniciando com a camada mais refinada da seção posterior. Nas camadas restantes, o número de refinamentos decresce gradativamente até a primeira camada localizada na seção anterior da retina. No caso de haver mais camadas do que o número de refinamentos na última camada, não scrão realizados refinamentos nas camadas iniciais do modelo. O refinamento do modelo é feito da seguinte forma: cada triângulo do modelo é dividido cm quatro novos triângulos, pegando-se os pontos médios de cada aresta e ligando-os, formando quatro novos triângulos no lugar do triângulo inicial. A figura 3.3 cxcmplifica o processo de refinamento. 


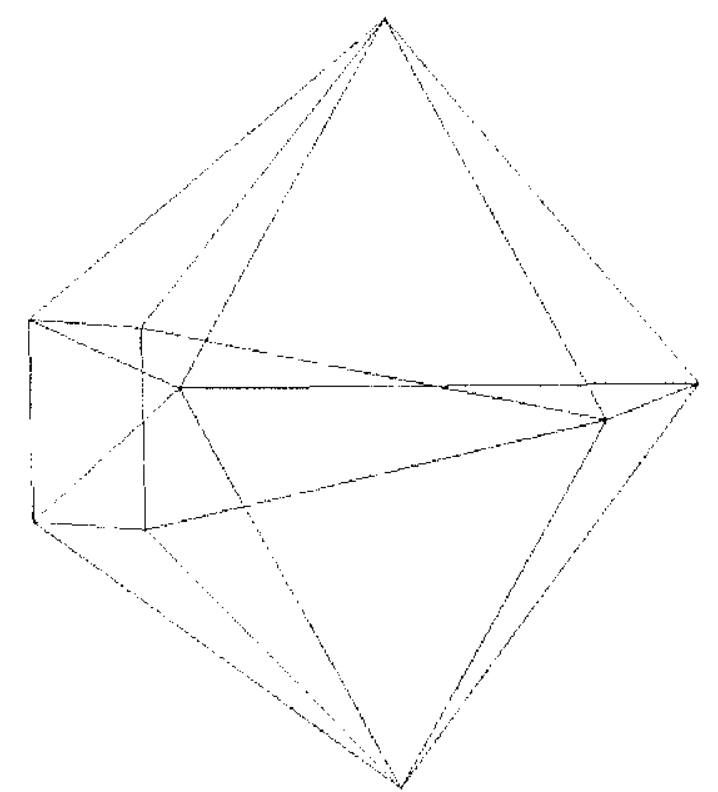

Figura 3,2: Etapa inicial da modelagem da retina com 2 camadas de refinamento

Figura 3.3: Processo de refinamento dos triângulos 


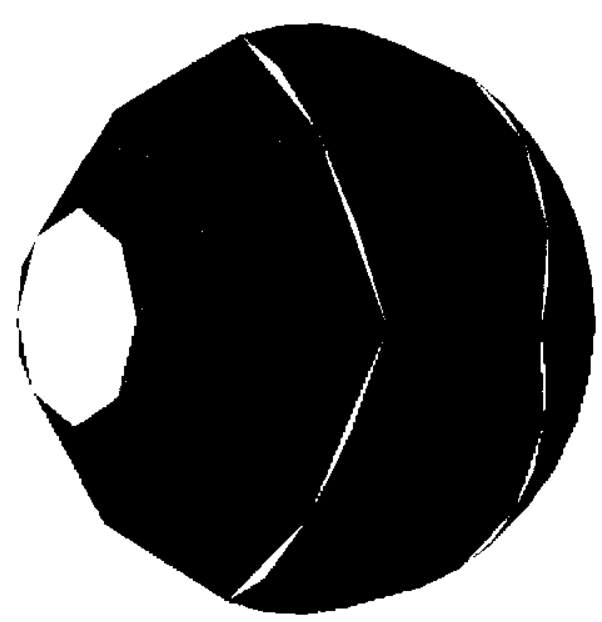

Figura 3.4: Modelo com três camadas e três refinamentos na última camada

Tendo calculado esses três novos pontos resultantes da subdivisão do triângulo, o próximo passo é deslocá-los para cima da esfera que define a retina, passo realizado utilizando o raio da esfera. Os únicos novos pontos que não são deslocados dessa mancira são aqueles que se encontram no plano da secção anterior do modelo. No caso desses pontos, $\mathfrak{e}$ feito um deslocamento para o círculo de secção, ao invés de para a circunferência da esfera. Após os diferentes números de refinamentos $\mathrm{em}$ cada camada, ainda restam buracos no modelo, existentes na fronteira entre duas camadas como é possível observar na figura 3.4.

Os buracos são corrigidos da seguinte maneira: tomam-se as arestas dos triângulos de fronteira das camadas onde foram realizados menos refinamentos (no caso do modelo com três refinamentos, a primeira e a segunda camadas), e verifica-se qual dessas arestas é formada pelos dois pontos de frontcira. Então, realiza-se uma divisão do triângulo de fronteira em questão em dois novos triângulos, através da divisão da aresta encontrada pela criação de um novo ponto na mediana da aresta e transportando-o para a circunferência da esfera. Quando o ponto é transportado, coincide com um ponto de fronteira da próxima camada, c dessa mancira o modelos fica livre de buracos.

Todo o processo de implementação foi feito utilizando $\mathrm{C}++$ como linguagem. A malha poligonal é escrita cm arquivo, usando como formato o tipo VTK Unstructured Grid. A escolha desse formato de arquivo deve-se principalmente a sua ampla utilização em ferramentas de visualização, 


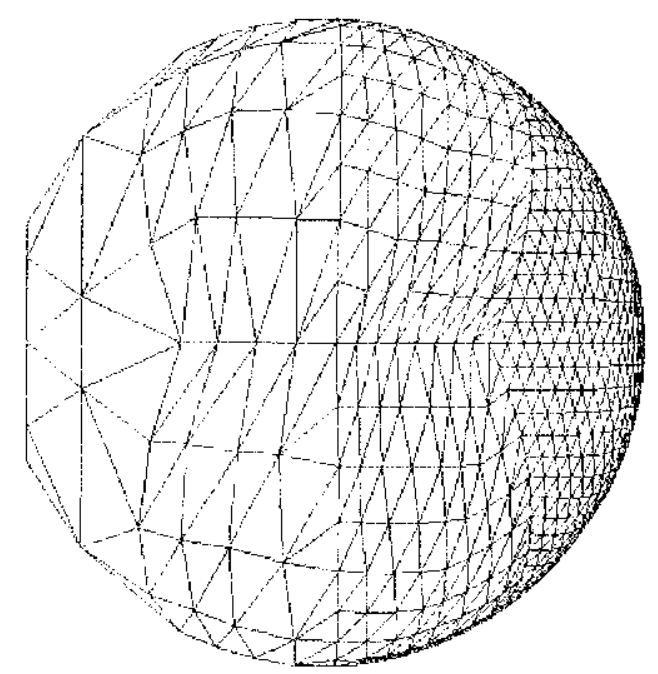

Figura 3.5: Modelo com três canadas e três refinamentos com os buracos corrigidos

bem como sua estrutura simples. Como alternativa, uma implementação utilizando o formato STL também é oferecida como opção. O formato STL possui a vantagem de já possuir todas as normais pré-calculadas no arquivo, cmbora tal facilidade acarretc um tamanho em disco muito maior se comparado ao formato VTK.

\subsection{Modelagem da Córnea}

O modelo da cónea foi construído com base nos dados obtidos pelo grupo de óptica oftalmológica da USP São Carlos através de topógrafos de cónea. Os dados estão contidos cm dois arquivos texto, um arquivo contendo 360 linhas, cada uma representando um grau da circunferência da cónea c contendo dezesscte valores de distância do ponto de maior clevação da cónea ao ponto em questáo. O primeiro valor de cada linha é scmprc zero pois representa a distância do ponto de maior clevação a cle mesmo. O ponto de maior clevação foi fixado como com coordenadas $x=0, y=0 \mathrm{c} z=0$. Como as distâncias entre pontos são representas em coordenadas polares, para obter as coordenadas y e $z$ de cada ponto foi necessário realizar uma conversão para coordenadas cartesianas. Para converter os valores contidos no arquivo, os quais estão cm pi- 


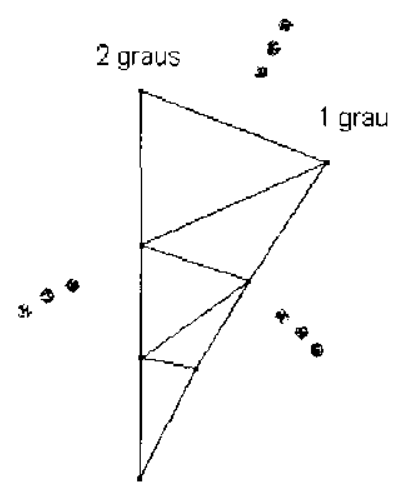

ponto de maior elevaçåo

Figura 3.6: Processo de triangulação da cónea

xels, foi necessário multiplicar tais valores por 0.024 , convertendo-os $\mathrm{cm}$ milímetros. O ângulo corresponde ao número da linha em que os cálculos cstão sendo realizados.

A coordenada $x$ de cada ponto do modelo é obtida utilizando o arquivo texto que representa clevação dc cada ponto cm relação ao ponto de maior elevação. Dessa forma, a coordenada $x$ é fornecida diretamentc no arquivo, bastando ser deslocada para encaixar-se no modelo da retina,o qual está centralizado nas coordenadas cartesianas. Finalmente, as coordenadas $x$ c $y$ são normalizadas para que o modelo fique centralizado, pois o ponto considerado como central é o de maior clevação, mas nem sempre esse ponto é o ponto central da córnea. Calculados os pontos, basta triangulá-los para obter o modelo completo, como visto na figura 3.6.

A triangulação gerada segue uma abordagem linear. Tal abordagem gera alguns problemas de ordem numérica ao aplicar os algoritmos de intersecção de polígono, pois a malha triangular produz triângulos muito alongados como visto na figura 3.7. Uma solução encontrada foi diminuir a resolução da malha, gerando triângulos mais uniformes como mostrado na figura 3.8. Obviamente tal solução proxluz uma perda na qualidade da malha c consequentemente um resultado menos fiel no cálculo da normal, embora nos tesıes realizados as malhas com menor resolução tenham apresentado resultados altamente satisfatórios. 


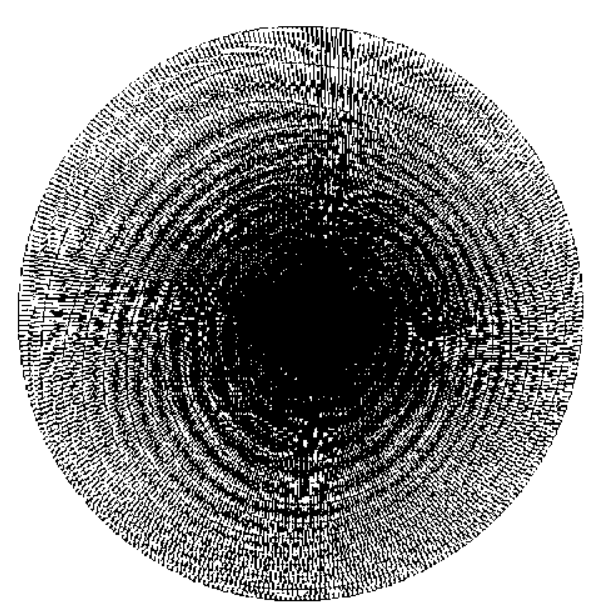

Figura 3.7: Cómea com ceratocone triangulada

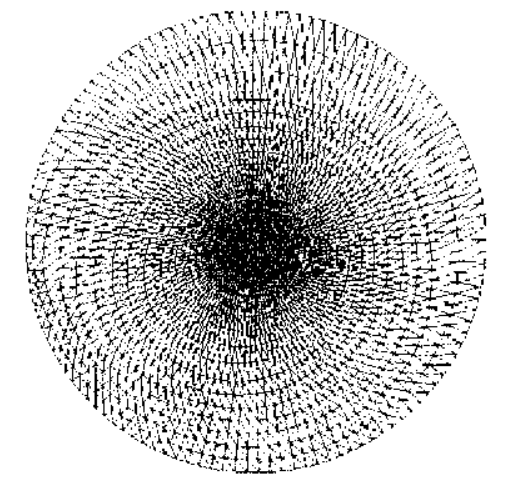

Figura 3.8: Cónea com ceratocone triangulada $\mathrm{cm}$ menor resolução 


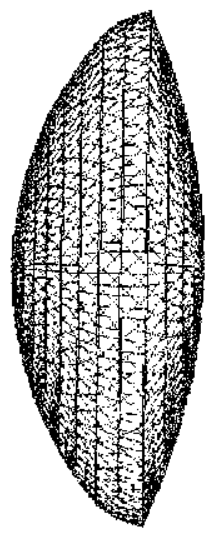

Figura 3.9: Modelo computacional das lestes do cristalino.

\subsection{Modelagem das lentes do cristalino}

A modelagem do cristalino seguiu o modelo proposto por Gullstrand (Gullstrand, 1909), onde o cristalino é modelado como um par de lentes, tendo a lente posterior um raio de curvatura de $6 \mathrm{~mm}$ c a lente anterior $10 \mathrm{~mm}$ de raio de curvatura, formando uma estrutura com aproximadamente 4 $m m$ de diâmetro cm seu centro. Apesar do modelo proposto por Gullstrand preconizar as lentes do cristalino como uma estrutura laminar dupla, uma abordagem de lâmina simples foi adotada pelo projeto, pois a adoção da estrutura mais complexa não afeta de maneira considerável a imagem final projetada na retina. A figura 3.9 apresenta o modelo computacional das lentes do cristalino $\mathrm{e}$ a figura 3.10 apresenta o modelo computacional final do sistema visual humano. 


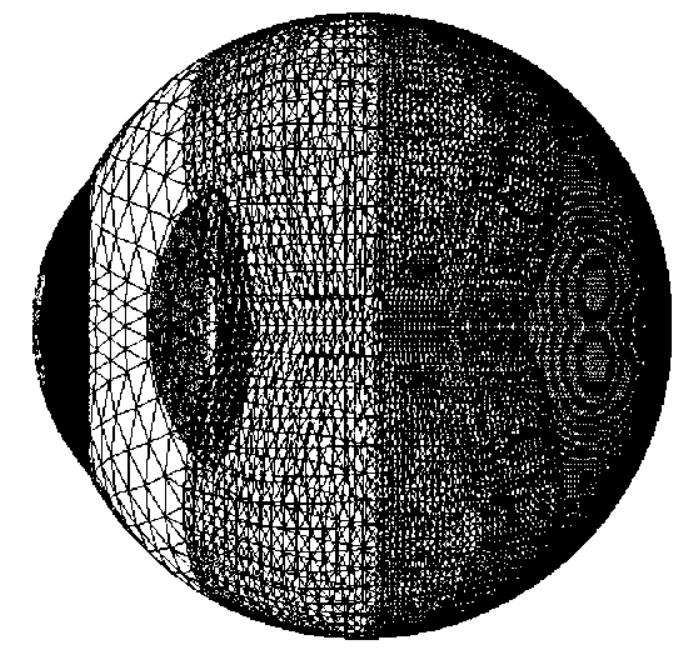

Figura 3.10: Modelo computacional final do sistema visual humano. 


\section{Capítulo 4}

\section{Lançamento de Raios}

O lançamento de raios, mais conhecido como ray-tracing, é um componente fundamental no processo de simulação do comportamento do sistema visual humano, pois este módulo é encarregado de modelar todas as leis físicas que regem o processo de intersecção dos raios de luz na cómea e cristalino e suas posteriores refrações. Este capítulo apresente a estrutura de dados topológica utilizada para armazenar as mahhas triangulares que modelam as estruturas anatômicas do olho humano. Posteriormentc o processo de intersceção dos raios com as malhas e o processo de refração dos raios de luz serão apresentados.

\subsection{Estrutura SHE}

Uma estrutura de dados topológica permite extrair do modelo representado todas as rclações de adjacência cntre as diferentes entidades topológicas presentes no modelo em tempo constante ou linearmente proporcional à incidência da entidade cnvolvida, ou scja, de forma independente da dimensão do problema, na medida em que as operações são realizadas loxalmente (Baumgart, 1975).

Quando se utiliza uma estrutura de dados topológica para geração ou manipulação de malhas, as principais características exigidas na estrutura são a capacidade de armazenar a malha geométrica permitindo uma manipulação dinâmica, inscrção e remoção das entidades que formam esta 
malha, e otimização nas buscas por informações topológicas, de vizinhanças e singularidade de vértices.

$\mathrm{Na}$ implementação da modelagem e posteriormente dos algoritmos de raytracing a estrutura de dados topológica Singular Handle-Edge (ct al, 2003), também conhecida como SHE foi empregada. Esta cstrutura foi bascada nas idćias de Nonato (L.G. Nonato, 2002), sendo utilizada para manipulação de malhas triangulares bi-dimensionais não estruturadas, permitindo assim uma maior otimização na geração e utilização desse tipo de malha.

A estrutura de dados topologica SHE foi implementada utilizando uma abordagem orientada a objetos. A figura 4.1 exemplifica as entidades estruturais da estrutura SHE. Segue-se uma breve apresentação de cada estrutura c o respectivo diagrama de classes na figura 4.2 .

- sheVertex: Esta classe representa cada vértice (ponto) de uma malha triangular. Esta representação ć feita armazenando as coordenadas geométricas, a característica de pertencer ao bordo ou não, informações sobre singularidade c um identificador. Um ponto de destaque nesta estrutura é a informação de singularidade que permite percorrer todo o link do vértice, mesmo este sendo um vértice singular.

- sheBoundary: Esta classe representa cada aresta de bordo de uma malha triangular. Outra informação armazenada aqui é uma referência ao bordo que cla perıence.

- sheBoundaryCp: Esta classe representa a(s) borda(s) de uma malha, cada componente conexo possui sua lista de componentes de borda (sheBoundaryCp), que por sua vez possui um ponteiro para uma lista de sheBoundary, que são as arestas da referida borda.

- sheSing: Cada sheVertex possui um ponteiro para uma lista de sheSing sendo armazenado nesta lista as arestas de bordo onde o vértice singular é pé, ou scja, percorrendo um ciclo anti-horário ao redor do vértice, é a primeira aresta encontrada. Quando a lista de sheSing possui mais de um clemento, podemos dizer que o vértice é singular, quando o vértice não é singular, se cle não estiver na borda ele tem na sua lista de sheSing uma aresta qualquer, mas se pertencer a borda, terá a aresta da borda. 


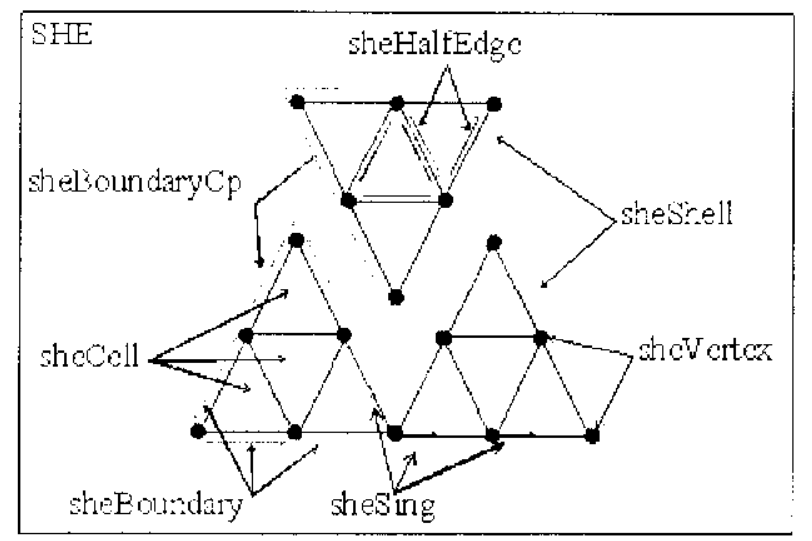

Figura 4.1: Malha triangular e entidades da estrutura

- sheHalfEdge: Esta classe representa cada semi-aresta dos triângulos da malha bi-dimensional Nesta entidade é annazenada a informação da célula a que ela pertence, da aresta vizinha e do vértice pé dá semi-aresta. A aresta vizinha pode pertencer a outro triângulo ou ao componente de bordo. Arestas pertencentes a dois triângulos, são representadas por dois objetos, um para cada triângulo.

- sheCell: Cada grupo de triângulos conexos é representado por esta classe. É nesta entidade onde são armazenadas as listas de células, e de componentes de bordo, além de um identificador, número de células, número de componentes de bordos e uma referência para a malha. Agrupando os triângulos desta mancira, por componentes conexas, temos que para cada Shell, existe apenas um componente de bordo externo, dentre todos bordos que este pode conter, sendo os outros componentes as bordas dos "buracos" na Shell.

- SHL: É a super classe que congrega todas as entidades da estrutura. Nesta classe se encontram as opcrações principais, como inserção e remoção de triângulos.

Uma funcionalidade muito interessante da implementação da estrutura de dados SHE é a possibilidade de utilizar iteradores para percorrer as estruturas da malha. Dessa mancira a tarefa de percorrer vértices, arestas, cstrelas de vértices, triângulos c outras estruturas reduz-se a um simples laço de iteração, dispensando à própria estrutura os controles necessários para executar a tarefa. 


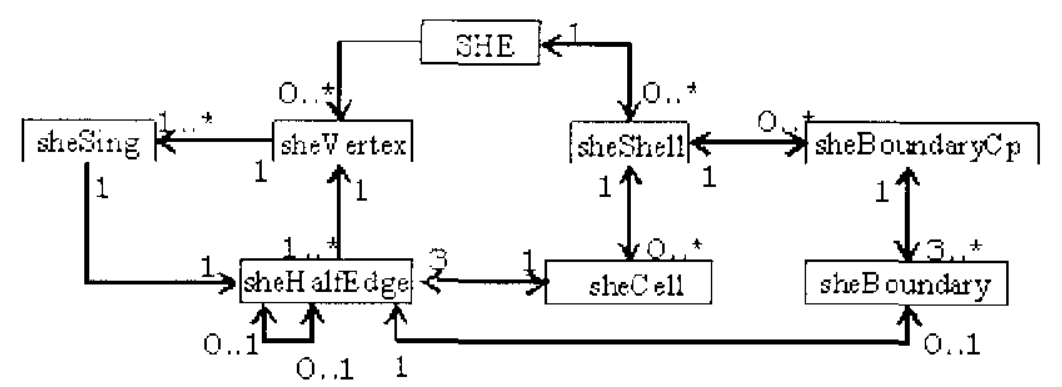

Figura 4.2: Diagrama de Classes da estrutura SHE

\subsection{Ray Tracing}

Com o uso da estrutura topológica Singular Handle-Edge foi possível executar com facilidade operações de busca na malha triangular. A primeira etapa do processo de lançamento de raios consiste em escolher os parâmetros da equação do raio a ser lançado na cómea,nesse caso o ponto inicial c sua direção. A ctapa seguinte consiste em encontrar o vértice que possui o menor ângulo em relação ao raio lançado dentro da malha da cómea. Essa ctapa introduz uma considcrávcl otimização no processo de raytracing, pois reduz o número de testes de intersecção com polígonos uma vez que em um esquema clássico, todos os triângulos da malha deveriam ser testados a fim de precisar qual desses triângulos é interceptado pelo raio. Na abordagem implementada apenas os triângulos localizados na estrcla do vértice com menor ângulo são testados, tornando o processo mais rápido e eficiente. Encontrar o vértice com o monor ângulo com o raio consistc cm traçar um vetor partindo do vértice testado até o ponto inicial do raio lançado c calcular o ângulo cntre csses dois raios através da equação 4.1. A seguir o mesmo cálculo é realizado para todos os vértices na estrela do vértice testado. Se algum desses vértices possuir um ângulo menor, então esse vértice torna-sc o vértice com menor ângulo e o processo é repetido. O processo termina quando ao analisar todos os vértices na cstrela do vértice atual, o valor do ângulo não diminui, pois provavelmente o vértice com o menor ângulo com o raio lançado foi encontrado. 


$$
\cos \theta=\frac{\overrightarrow{v 1} \cdot \overrightarrow{v 2}}{|\vec{v}| \cdot|\overrightarrow{v 2}|}
$$

O algoritmo de teste de intersecção utilizado nas implementações está bascado no algoritmo de Badoucl (Badouel, 1990). O algoritmo fornecc um método simples c eficiente de calcular a interseç̧ão de um raio com um polígono, no caso triângulos. O método está dividido em duas etapas: primeiramente é testado se o raio intercepta ou não o plano que contém o polígono; a scgunda etapa consiste $\mathrm{cm}$ detcrminar as coordenadas da intersecção caso a primeira ctapa tenha tido resposı positiva.

A etapa de teste de intersecçăo consiste em primeiramente em computar o vetor normal ao plano contendo os vértices do triângulo testado. Sendo $V_{0}, V_{1} \mathrm{e} V_{2}$ os vértices do triângulo e $\mathbf{N}$ a normal ao plano tcmos na equação 4.2 :

$$
\overrightarrow{\mathbf{N}} \cdot \overrightarrow{V_{0} V_{1}} \times \overrightarrow{V_{0}} W_{2}
$$

Para cada ponto $I^{\prime}$ pertencente ao plano, o produto $I^{\prime} \cdot \mathbf{N}$ ć constante, scndo tal valor calculado pclo produto escalar $d-V_{0} \cdot \mathbf{N}$. Tomando a representação implícita do plano na equação 4.3 c a represcntação paramćtrica da reta na equação 4.4, onde $O$ é o ponto de origem do raio $c D$ é a dircção, substituindo $P$ na equação 4.3 pela representação paramétrica do raio e isolando o parâmetro $l$, temos a equação 4.5 :

$$
\begin{aligned}
& \mathbf{N} \cdot P+d=0 \\
& r(t) \cdots O+D t \\
& t=-\frac{d+\mathbf{N} \cdot O}{\mathbf{N} \cdot D}
\end{aligned}
$$

Utilizando a equação 4.5 é possível chegar às seguintes conclusões: 


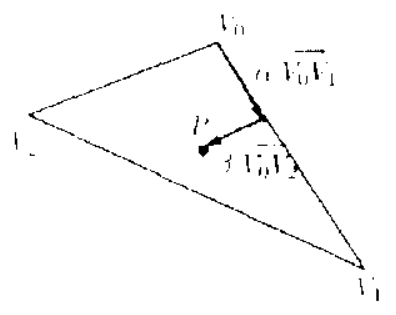

Figura 4.3: Coordenadas do ponto $\mathrm{P}$

- Se o polígono e o raio são paralelos $(N \cdot D=0)$ a intersecção é rejeitada

- Se a intersecção é anterior à origem do raio $(l<0)$ a intersecção é rejeitada

- Se uma intersecção mais próxima já foi calculada $\left(t>t_{\text {ray }}\right)$ a intersecção é rejeitada

A segunda ctapa consiste em detcrminar as coordenadas do ponto de intersecção no polígono. Como exemplificado na figura 4.3 o ponto $P$ é dado pela equação 4.6 .

$$
\overrightarrow{V_{0} P}=\alpha \overrightarrow{V_{0} V_{1}}+\beta \overrightarrow{V_{0}} \overrightarrow{V_{2}}
$$

O ponto $P$ estará dentro do triângulo se $\alpha \geq 0, \beta \geq 0$, e $\alpha+\beta \leq 1$. A equação 4.6 possui três componentes (equação 4.7) e admite uma solução única.

$$
\left\{\begin{array}{l}
X_{p}-X_{0}=\alpha\left(X_{1}-X_{0}\right)+\beta\left(X_{2}-X_{0}\right) \\
Y_{p}-Y_{0}=\alpha\left(Y_{1}-Y_{0}\right)+\beta\left(Y_{2}-Y_{0}\right) \\
Z_{p}-Z_{0}=\alpha\left(Z_{1}-Z_{0}\right)+\beta\left(Z_{2}-Z_{0}\right)
\end{array}\right.
$$

De modo a reduzir o sistema, o polígono é projetado $\mathrm{cm}$ um dos planos $x y, x z$ ou $y z$. Todavia, é necessário descobrir qual o eixo dominante do vetor normal e usar o plano perpendicular a esse cixo de modo a maximizar a projeção. Computando o valor $i_{0}$, 


$$
i_{0}=\left\{\begin{array}{ccc}
0 & \text { se } & \left|\mathbf{N}_{x}\right|=\max \left(\left|\mathbf{N}_{x}\right|,\left|\mathbf{N}_{y}\right|,\left|\mathbf{N}_{z}\right|\right) \\
1 & \text { se } & \left|\mathbf{N}_{y}\right|=\max \left(\left|\mathbf{N}_{x}\right|,\left|\mathbf{N}_{y y}\right|,\left|\mathbf{N}_{z}\right|\right) \\
2 & \text { se }\left|\mathbf{N}_{x}\right|-\max \left(\left|\mathbf{N}_{x}\right|,\left|\mathbf{N}_{y}\right|,\left|\mathbf{N}_{z}\right|\right)
\end{array}\right.
$$

Considerando $i_{1} \mathrm{c} i_{2}$ como índices diferentes de $i_{0}$, eles representam o plano primário usado para projetar o polígono. Scja $(u, v)$ a coordenada bi-dimensional de um vetor nesse plano; as coordenadas de $V_{0} I^{3}, \overrightarrow{V_{0} V_{1}}$ e $\overrightarrow{V_{0}} \overrightarrow{V_{2}}$, projetadas nesse plano são:

$$
\begin{array}{lll}
u_{0}=I_{i_{1}}^{\prime}-V_{0_{i 1}} & u_{1}-V_{1_{i 1}}-V_{0_{i 1}} & u_{2}=V_{2_{i 1}}-V_{0_{i 1}} \\
v_{0}=P_{i_{2}}-V_{0_{i 2}} & v_{1}=V_{1_{i 2}}-V_{0_{i 2}} & v_{2}=V_{2_{i 2}}-V_{0_{i 2}}
\end{array}
$$

Logo, a equação 4.7 reduz-se a

$$
\left\{\begin{array}{l}
u_{0}=\alpha \cdot u_{1}+\beta \cdot u_{2} \\
v_{0} \quad \alpha \cdot v_{1}+\beta \cdot v_{2}
\end{array}\right.
$$

As soluções são

$$
\alpha=\frac{\operatorname{det}\left(\begin{array}{ll}
u_{0} & u_{2} \\
v_{0} & v_{2}
\end{array}\right)}{\operatorname{det}\left(\begin{array}{ll}
u_{1} & u_{2} \\
v_{1} & v_{2}
\end{array}\right)} \quad \epsilon \quad \beta=\frac{\operatorname{det}\left(\begin{array}{ll}
u_{1} & u_{0} \\
v_{1} & v_{0}
\end{array}\right)}{\operatorname{det}\left(\begin{array}{ll}
u_{1} & u_{2} \\
v_{1} & v_{2}
\end{array}\right)}
$$

Após o cálculo da coordenada do ponto de intersecção na cónca, é realizado o cálculo da normal interpolada nos três vếrtices que compõe o triângulo no qual o ponto cstá contido.Posterionnente é computado o valor da normal no ponto utilizando coordenadas baricêntricas, pois esse método fomece um cálculo mais exato da normal no ponto. Seguindo os princípios opticos da refração, a lei de Snell é usada para calcular o desvio e o novo raio que irá incidir sobre a retina. A figura 4.4 mostra o processo de reflexão do raio incidente na cónea. O raio refratado $T$ é calculado através 


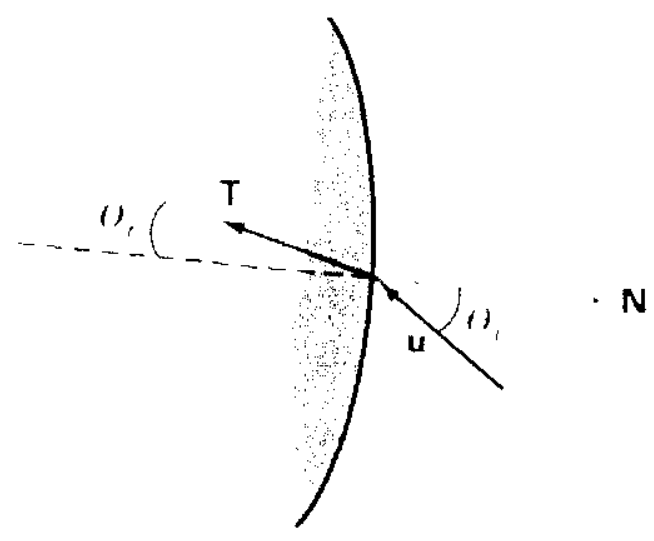

Figura 4.4: Esquema do processo de refração do raio incidente na cónea

da cquação 4.11 (D. Hearn, 1997) utilizando o raio incidentc $u$ e na normal no ponto de intersecção da cómea N. A lei de Snell (cquação 4.12) é utilizada para calcular o ângulo de refração $0_{r}$

$$
\begin{aligned}
& \text { T } \frac{n_{i}}{n r} u-\left(\cos \theta_{r}-\frac{n_{i}}{n r} \cos \theta_{i}\right) \mathbf{N} \\
& \cos \theta_{r}=\sqrt{1-\left(\frac{n_{i}}{n_{r}}\right)^{2}\left(1-\cos ^{2} \theta_{i}\right)}
\end{aligned}
$$

Todo o processo apresentado anteriormente é repetido para calcular o ponto de intersecção do raio refratado na retina. 


\section{Capítulo 5}

\section{Resultados}

Com o intuito de apresentar os resultados alcançados através do modclagem computacional do sistema visual humano descrita anteriormente, diversas simulaçōes c validaçōes foram implementadas. Tais simulaçōes têm por objetivo investigar os efeitos das irregularidades presentes na cónea na formação da imagem retinal. Este capítulo apresenta tais simulaçŏes, as quais variam desde simples lançamentos de feixes de raios até a projeções de imagens reais na retina.

\subsection{Lançamento dos Anéis de Plácido}

Após a construção de todo o arcabouço computacional necesário para implementar as características geométricas $\mathrm{c}$ as funcionalidades opticas presentes no olho humano, algumas simples simulações foram realizadas de modo a aferir a robustez e corretudo do modelo computacional implementado.

Uima das mais simples simulações descrita na literatura é o chamado lançamento dos anéis de Plácido (Placido, 1880). Nesta simulação um feixe de anéis concêntricos de raio variávcl é projetado na superfície da cornea, de maneira a observar a projeção de tais anéis na superfície retinal. A figura 5.1 ilustra a projeção dos anéis na superfície da cónea e a figura 5.2 ilustra o processo de refração dos raios de luz dentro do olho humano. Apesar da simplicidade de tal simulação, é importante ressaltar que a mesma apresenta resultados interessantes ao observar efeito 


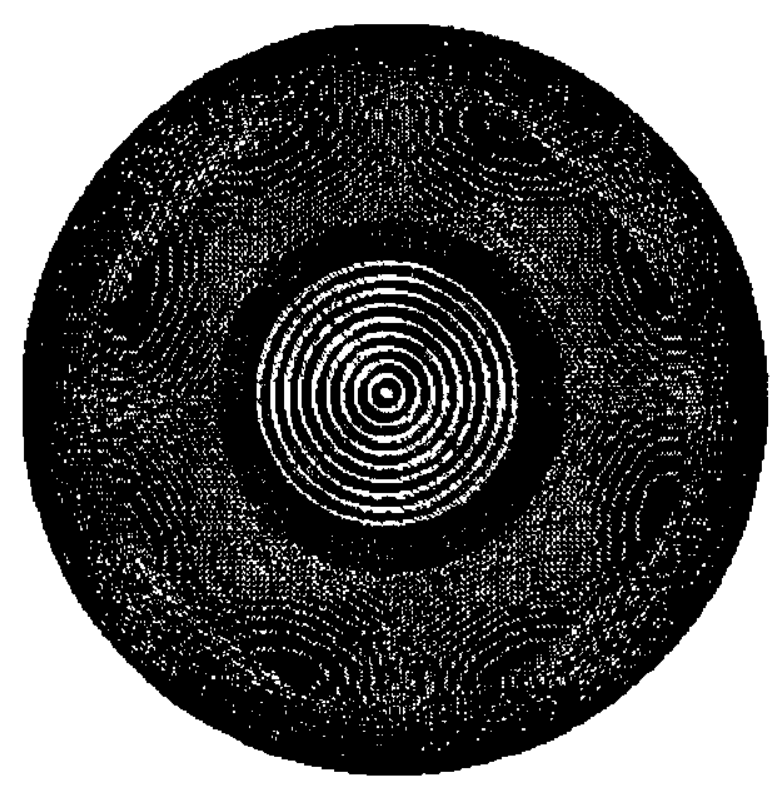

Figura 5.1: Projeção dos Anéis de Plácido na Córnea

das irregularidades da córnea na formação da imagem retinal. A figura 5.3 mostra a projeção dos anéis no fundo da retina através de uma córnea hemétrope, aqui presentemente designada como tcórica, pois está livre de quaisquer imperfeições em sua superfície. Como esperado, o lançamento dos anéis formou uma projeção uniforme e focalizada na região da fovea centralis. Entretanto, ao utilizar uma cornea com uma deformação $\mathrm{cm}$ sua superfícic, mais espccificadamente um ceratocone, é possível notar na figura 5.4 uma completa disperção dos raios de luz na projeção retinal. Tal dispersão dos raios de luz também pode ser encontrada nas projeções realizadas tanto em córneas com astigmatismo forte 5.5 , quanto $\mathrm{cm}$ cóncas com astigmatismo suave 5.6. Tais resultados corroboram para a importância da cómea na formação da imagem retinal.

\subsection{Simulaçào de Inversão de Imagem}

De modo a verificar a corretude das funcionalidades opticas implementadas no modelo computacional do sistema visual humano, uma simples simulação de lançamento de raios foi realizada 


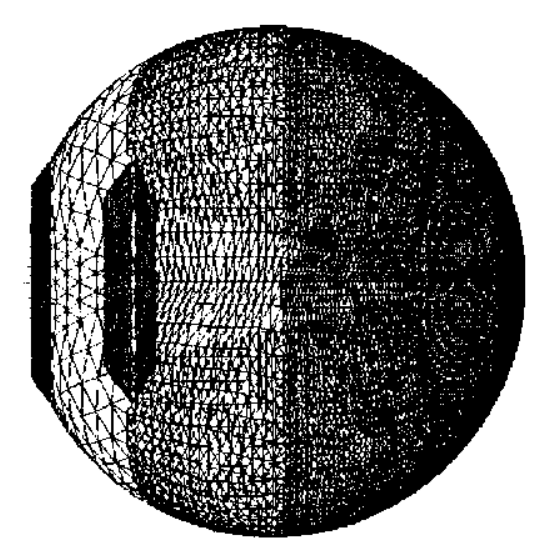

Figura 5.2: Esquema do processo de lançamento e refração de raios no interior da superfície ocular

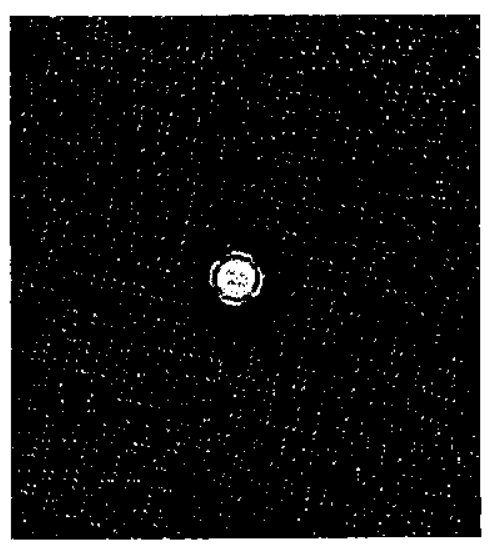

Figura 5.3: Imagem retinal formada através da projeção dos anćis de Plácido em uma córnea normal 


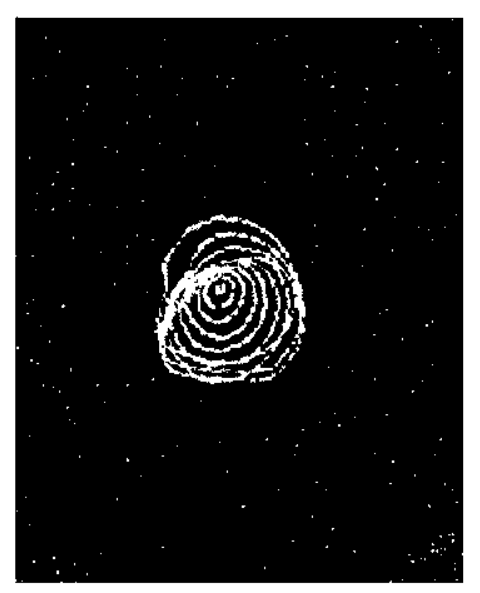

Figura 5.4: Imagem retinal formada através da projeção dos anéis de Plácido em uma córnea com ceratocone

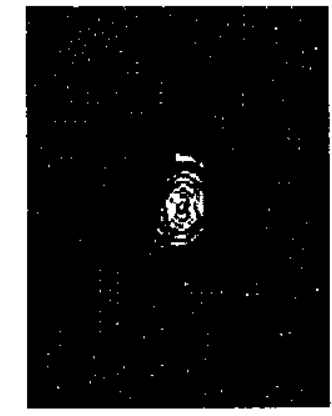

Figura 5.5: Imagem retinal formada através da projeção dos anéis de Plácido cm uma cónea com astigmatismo forte

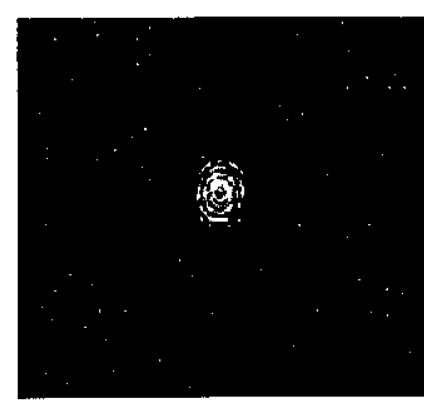

Figura 5.6: Imagem retinal formada através da projeção dos anćis de Plácido em uma cónea com astigmatismo suave 


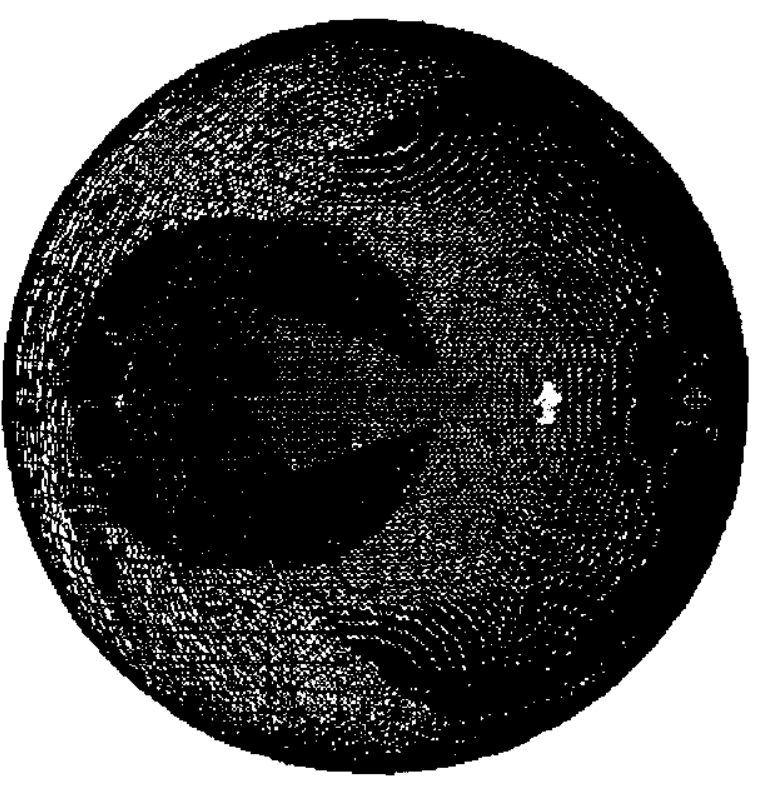

Figura 5.7: Lançamento de raios a partir de um objeto com orientação definida em vista lateral

de modo a aferir o processo de inversão da imagem retinal, fenômeno esse amplamente conhecido pela comunidade científica. A simulação foi realizada com base em um objeto com orientação definida, no caso uma figura ilustrativa de uma seta. A figura 5.7 ilustra $\mathrm{cm}$ verde o caminho percorrido pelos raios de luz e a clara inversão da imagem ocorrida no fundo da retina. A fim de investigar a contribuição de irregularidades na cornea, as figuras $5.8,5.9$ c 5.10 ilustram o processo de lançamento de objeto com orientação definida $\mathrm{em}$ córneas normais, com ceratocone $\mathrm{c}$ astigmatismo forte, respectivamente.

\subsection{Point Spread Function}

Na literatura médica que trata de temas ligados à acuidade visual de pacientes, é comuın encontrar o mapa denominado Point Spread Function, o qual pode ser descrito de mancira simplificada como um mapa que determina quão bem a cónica foca os raios de luz na região da fovea. 


$$
\frac{-}{\vdots}
$$




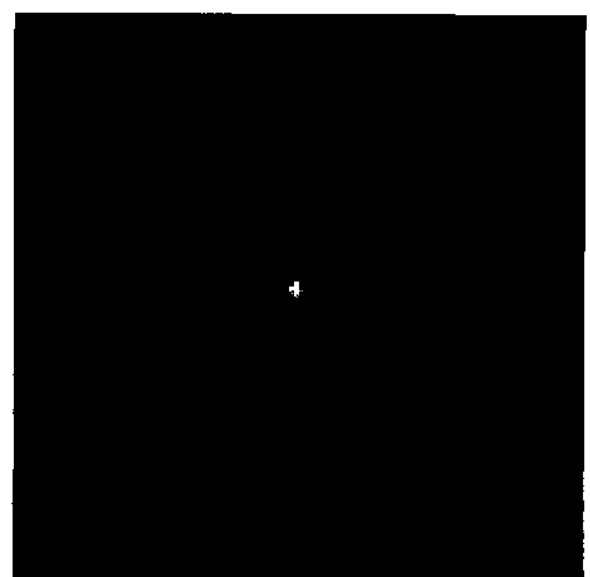

Figura 5.11: Mapa de Point Spread Function produzido a1ravés de uma cónea hemétrope perfeita.

Para tanto, é determinado um raio base localizado no ponto de melhor foco e os demais raios são comparados a esse raio base. Um olho teórico perfeito iria focalizar a maioria dos raios na região do raio de melhor foco, enquanto cóneas com deformidades produzirăo um mapa com menor intensidade no ponto de melhor foco e muitos raios esparsos. A figura 5.11 apresenta a Point Spread Function de uma cónea teórica de $7.5 \mathrm{~mm}$ de raio de curvatura. Como dito anteriormente, a grande maioria dos pontos estão focados no ponto de melhor foco. Ja a figura 5.12, onde uma cónea com ceratocone foi utilizada, apresenta um padrão completamente disperso na localização dos pontos de luz, sendo que uma quantidade elevada de pontos está muito distante do ponto de melhor foco. A figura 5.13 apresenta o mapa de Point Spread funcion de uma cornea com astigmatismo forte, onde é possível notar que apesar de uma melhor concentraçăo dos raios na região central de melhor foco, alguns raios ainda atingem regiões periféricas da retina. Uma interpretação bastante razoável para tais dados é de que quanto mais dispersos os pontos se apresentarem no mapa da Point Spread Function pior será a acuidade visual do indivíduo estudado. Os resultados obtidos pelo simulador condizem com dados apresentados na literatura, tais como as simulações de Camp (J.J. Camp, 1990) discutidas anteriormente. 


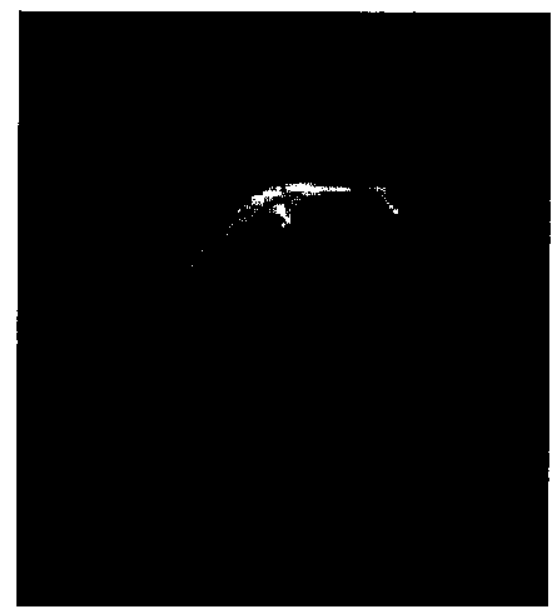

Figura 5.12: Mapa de Point Spread Function produzido através de uma cónea com ceratocone.

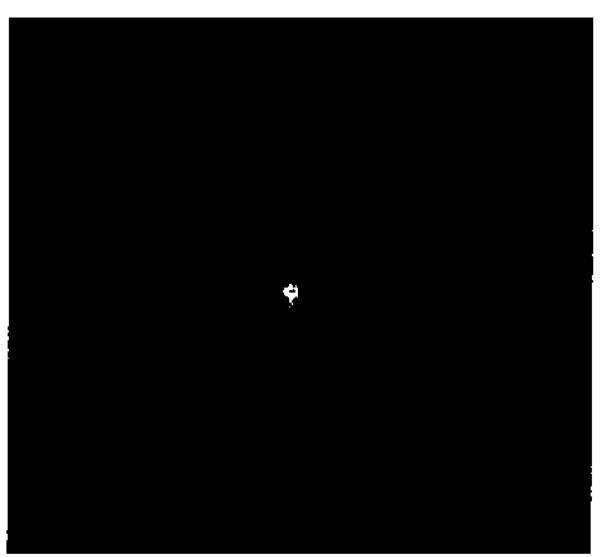

Figura 5.13: Mapa de Point Spread Function produzido através de uma córnea com astigmatismo fortc. 


\subsection{Simulação de Wavefront}

Uma das mais importantes técnicas no diagnostico de pacientes na atualidade é o exame denominado Wavefront, ou exame de frente de onda. Através dessa técnica é possível identificar um número grande de deficiências, tais como distorção de campo ou coma, onde anteriormente os métodos usuais de diagnostico apenas identificavam miopia, astigmatismo c hipermetropia. Nos casos em que a cirurgia é indicada, o wavefront e também capaz de determinar o ponto cxato da ablação (retirada do tecido da cómea).

Dada a importância da técnica de wavefront, foi implementada uma versão computacional do processo, fomeccndo dados para quaisquer tipo de análises. A implementação foi feita através da comparação do caminho ótico de um raio base, o qual percorre um caminho sem reflexão dentro do olho humano, pois scu ângulo de incidência com a superfícic é de 90 graus, com os demais raios provenientes de um feixe de luz. Ao igualar o comprimento ótico dos raios de luz lançados com o comprimento ótico do raio base, é possível traçar um comprimento ótico para cada raio , formando uma frente de onda logo após o cristalino. Uma importante análise proveniente do processo de wavefront é a possibilidade de validar o modelo computacional implementado através da comparaçăo de dados provenicntes de um aberrômetro $\mathrm{cm}$ um modelo mecânico de olho.

Recentemente, Thibos (Larry N. Thibos, 2003) excmplifica em scu artigo uma séric de métricas que podem ser relativamente facilmente implementadas a partir de dados provenientes de um wavefront. Todavia, cabe ressaltar que tal implementação computacional ainda não pode substituir ficlmente os modernos aparelhos de wavefront disponíveis, uma vez. que existem fenômenos ligados ao cristalino que não foram abrangidos pelas simulações, uma vę que o modelo computacional dispõe de um modelo teórico do cristalino. O estudo de um mecanismo eficiente de aquisição de dados in vivo, ou simulações mais realistas das aberraçōes do cristalino constitucm em uma futura cvolução no estudo da área de simulação computacional do sistema visual humano. A figura 5.14 exemplifica o processo de wave-front, onde é possível abstrair o formado da frente de onda de luz após ser refratada pelo cristalino. 


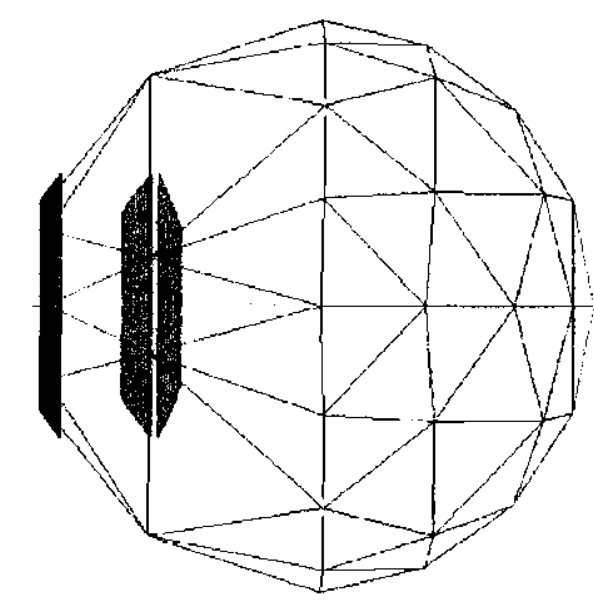

Figura 5.14: Ilustração do processo de obtenção da frente de onda.

\subsection{Simulação de Projeção de Imagens}

Uma das mais interessantes simulações realizadas com a ajuda do simulador do sistema visual humano foi a projeção de imagens reais na retina. Tal tipo de projeção é inédita na literatura pois em trabalhos relacionados as imagens eram projetadas em um plano no local de melhor foco no fundo da retina, c não na retina propriamente dita, ignorando as deformações geométricas implícitas. Tão pouco $\mathrm{cm}$ outros trabalhos corrclatos é possível abstrair dirctamente a imagem retinal a partir de deformidades na córnea, sendo técnicas altenativas utilizadas, tais como a convolução de uma imagem com a sua Point Spread Funcion. Todavia, cabe salientar que tais imagens não são totalmente fidedignas, ou scja, tal simulação não tem como objetivo "ver o que o indivíduo vê", pois uma séric de questões presentes no sistema orgânico real não foram abordadas, tais como anormalidades no cristalino c outros tipos de aberraçōes, bem como o modo cm que os raios de luz chegam à cómea. Em um ambiente real infinitos raios de luz emanam de cada ponto de uma imagem, formando um cone de raios para cada ponto. Tal abordagem produz o efeito de borramento presente em imagens reais, sobretudo nos individuos com deformidades na córnea. A abordagem mais simples adotada na simulação produz um feixe de raios paralelos, onde cada ponto da ima- 


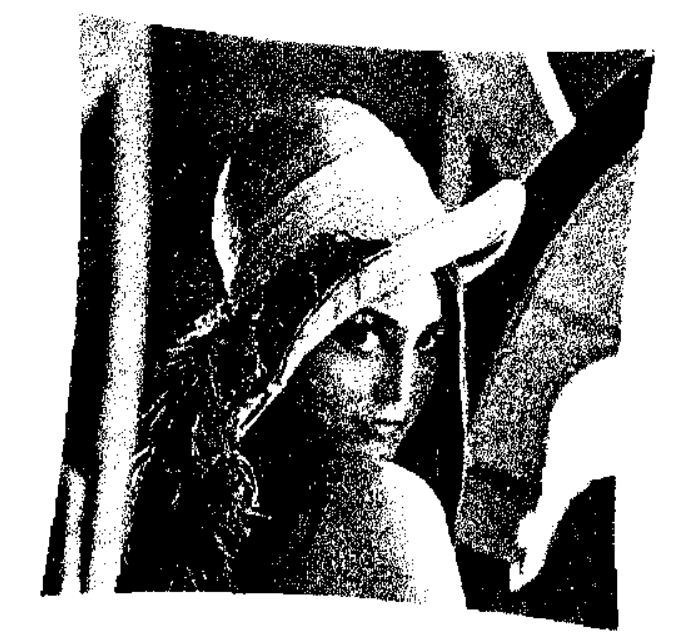

Figura 5.15: Imagem projetada na retina através de uma córnea nromal.

gem produz apenas um raio, tal como se a imagem emanasse de um raio lazer diretamente para 0 olho do indivíduo estudado. Apesar de tais limitações é possível observar resultados interessantes c pertinentes no estudo do sistema visual humano.

A figura 5.15 apresenta uma imagem real projetada através de uma córnea hemétrope perfeita. Ao comparar a imagem projetada com a original mostrada na figura 5.16 é possível observar que apesar de fiel à imagem original, algumas distorções geométricas estão presentes na imagem projetada na retina. A imagem projetada através de uma cónca com ceratocone, obscrvada na figura 5.17 apresenta um alto grau de deformação, sendo mais saliente as deformações nos cantos da imagem, bem como alterações em linhas retas c alterações de proporções. 


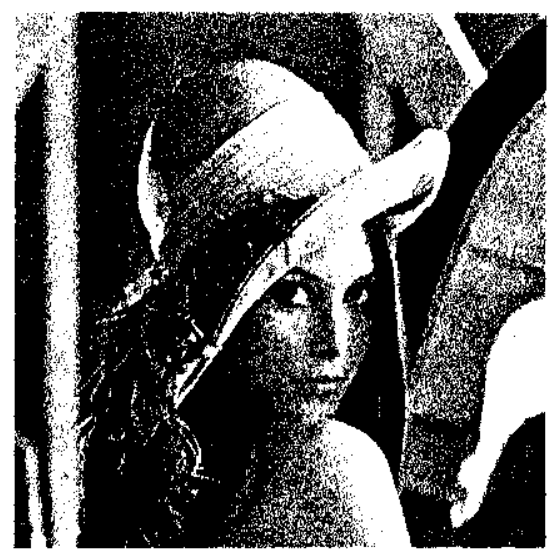

Figura 5.16: Imagem original utilizada para projeção.

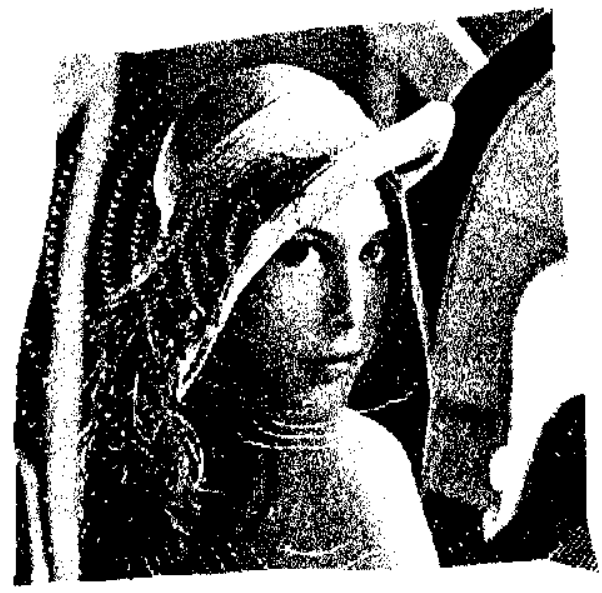

Figura 5.17: Imagem projetada na retina através de uma cómea com ceratocone. 


\section{Capítulo 6}

\section{Conclusão e Trabalhos Futuros}

O projeto de mestrado explora uma árca ainda em desenvolvimento, pois apenas recentemente foi possível agregar dados obtidos in vivo de pacientes para construir um modelo computacional mais realístico do sistema visual humano. Embora muitas ctapas ainda devam ser trilhadas até tais simulações poderem com confiança predizer a acuidade visual do paciente e fornecer métodos seguros de diagnósticos, os resultados obtidos pelo projeto são encorajadores, fornecendo um arcabouço computacional agil, robusto e flexível que poderá ser utilizado para o estudo de fenômenos ligados ao sistema visual humano ainda pouco compreendidos.

Uma vasta gama de trabalhos futuros podem advir do aprofundamento e evolução da modelagem e simulação do sistema visual humano implementada pelo projeto. O passo mais imediato da evolução é a aquisição de dados in vivo das lentes do cristalino. Atualmente os instrumentos que possibilitariam a aquisição de tais dados, através de ultrasonografia, não possuem a precisão necessária para a modelagem real e fidedigna da estrutura das lentes do cristalino. Outro ponto complexo é a modelagem do sistema de acomodação das lentes do cristalino, ponto de muita controvérsia na literatura atual.

Vislumbrando um futuro sistema que agregue as mais importantes estruturas oculares com dados reais c consistententes, o estudo da simulação do sistema visual humano avançaria para campos ligados ao córtex visual do cérebro humano, estudando e simulando seu comportamento. 


\section{Bibliography}

B. Barsky, D. Garcia, S. K. (1998). Cwhatuc: A visual acuity simulator. Proceedings of Ophthalmic The cnologies, VIII:290-298.

Badouel, D. (1990). Graphics Gems, volume IV, chapter 7, pages 390-393. AP Professional.

Baumgart, B. (1975). A polyhedron representation for computer vision. AFIPS National Computer Conference, 44:589-596.

D. Hearn, M. B. (1997). Computer Graphics C Version. Prentice-Hall, 2nd edition.

Emsley, H. H. (1952). Visual Optics. Hatton Press Ltd, 5th edition.

ct al, L. N. (2003). Topological approach for detecting objects from images. Proceedings of SPIE.

Gullstrand, A. (1909). Helmholtz's Handbuch der Physiologischen Optik, volume 1. 3rd edition.

Helga Kolb, Eduardo Fernandez, R. N. (2004). Webvision. Intemet.

J. Doshi, J. Sarver, B. A. (2001). Schematic eyes models for simulation of patient visual performance. Journal of Refractive Surgery, 17:414-419.

J.J. Camp, L.J. Maguirc, c. a. (1990). A computer model for the evaluation of the effect of comeal topography on optical performance. American Journal of Ophthalmology, 109(4):379-385.

Kooijman, A. C. (1983). Light distribution on the retina of a wide-angle theoretical cye. $J O p t$ Soc Amer, 73:1544-1550. 
L. Carvalho, P. Saia, c. a. (2002), A ray tracing simulation of visual performance of the human eyc using in vivo corneal topography. Optics.

L. Thibos, X. Zhang, A. B. (1992). The chromatic eye: a new reduccd-cyc model of ocular chromatic abcrration in humans. Appl Opt, 31(19):3594-3600.

L. Thibos, X. Zhang, A. B. (1997). Spherical aberration of the reduced schematic eye with elliptical refracting surface. School of Optomctry.

Larry N. Thibos, Xin Hong, A. B. c. a. (2003). Metrics of optical quality of the cyc. Association for Research in Vision and Ophthalmology Annual Meeting Abstracts, 10:1 167-1181.

L.G. Nonato, A. Castclo, M. O. (2002). A topological approach for handling triangle inscrtion and removal into two-dimensional unstructured meshes. Cadernos de Computação do ICMC. USP/São Carlos, 2(3):221-244.

L.N. Thibos, A. (1999a). Visual Instrumentation: Optical design and engeneering principles, chapter 4, pages 101-159. McGraw-Hill.

L.N. Thibos, Y. W. (1999b). Oblique (off-axis) astigmatism of the reduced schematic eyc with elliptical refracting surface. Technical report, School of Optomctry, Indiana, IN.

Lotmar, W. (1971). Theoretical eye model with aspherics surfaces. J Opt Soc Amer, 61:15221529.

Pedrotti, L. (1998). Optics and Vision, chapter 10, pages 194-223. Prenticc-Hall.

Placido, A. (1880). Novo instrumento de exploração da cónea. Periodico d'Oftalmológica Practica, 5:27-30.

R. Navarro, J. Santamria, J. B. (1985). Accommodation-dependent model of the human cyc with aspherics. J Opt Soc Amer A, 2(8):1273-1281.

Smith, G. (2003). The optical properties of the crystalline lens and their significance. Clinical and Experimental Optometry, 86:3-18. 
von Helmholtz, H. (1909). Physiologic Optics, volume 1 and 2. 3rd edition. 